\title{
In Situ Changes in the Moisture Content of Heated, Welded Tuff Based on Thermal Neutron Measu:ements
}

\author{
Abelardo L. Ramirez \\ Richard C. Carlson \\ and \\ Thomas A. Buscheck
}

Manuscript Date: May 1990

Publication Date: July 1991

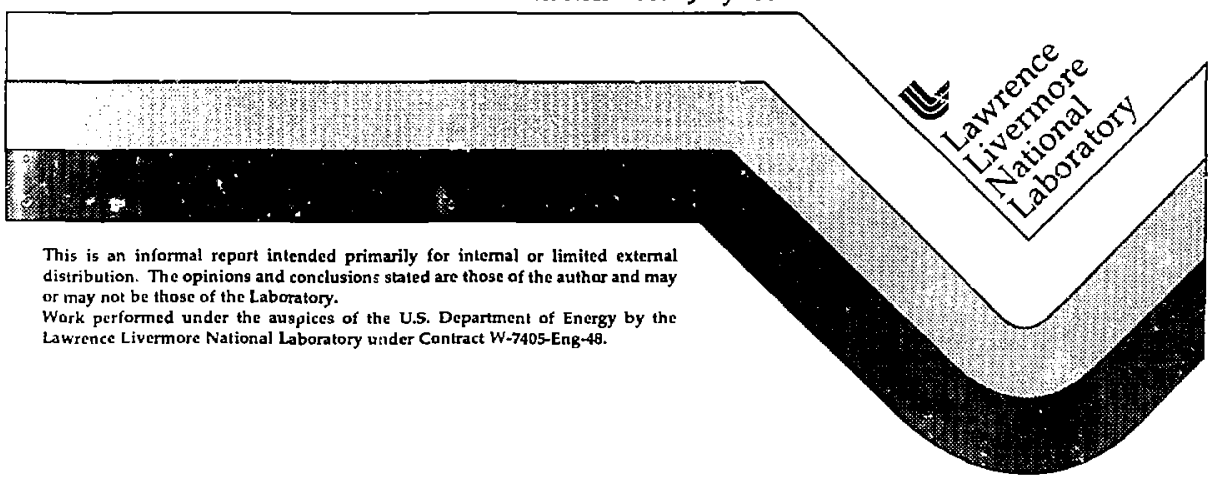




\section{DISCLAIMER}

This document was frepared as an acccount of work sponsoted by an ageney of the Linited States Government. Nejther the United States Coverument nor the University of California nor any of their employees, makes any warranty. express or implied, or assumes any legal liability or responsibility for the accuracy, completeness, or usefulness of any information. apparatus, produet, or prosess disclosed. or represents that its use would not infringe privately own rights. Reference herein to any specific commercial products, process, or service by trade name, trademark, manufacturex, or otherwise, does not necessarily constitule or imply its endursement, recoinmendation, or favoring by the United States Governmenl or the University of California. The views and opinions of authors expressed herein do not necessarily statc c: reflect those of the United States Government ur the University of Califurnia, and shall not be used for advertisulg or product endorsement purposes.

This report has been reproduced directly from the best available copy.

A vaiiable to DCE and DOE contraciors frum the Office of Sxientific and Technical Information

P.O. Eox 62, Dak Ridge, TN 37B31

Prices available from (615) 576-8401, FT5 626-6401

Available to the publis from the

National Technical Information Service

U.S. Department of Commerce

5285 Port Royal Rd.

Springfield, VA 22161

Prepared by Yucca Mountain Site Characterization Project (YMP) participants as part of the Civilian Radioactive Waste Management Program. The YMP is managed by the Yucca Mounlain Site Characterization Project Office of the U.S. Departmenl of Energy, Las Vegas, Nevada 
IN SITU CHANGES IN THE MOISTURE CONTENT OF HEATED, WEI.DED TUFF BASED ON THEBMAL NEUTRON MEASUREMENTS

\author{
Abelardo L. Ramirez, Richard C. Carlson and Thomas A. Buscheck
}

\title{
Abstract
}

UCRL-ID- -104715

\section{Abstract}

DE91 017526

Thermal neutron logs were collected to monitor changes in moisture content within a welded tuff rock mass heated from a borehole containing an electrical heater which remained energized for 195 days. Thermal neutron measurements were made in sampling boreholes before, during and atter heating. For each sampling borehole, the differences between the "before" and "after" measurements were calculated. The possibility of changes in the moisture content of the grout column within the sampling borehiles introduces an unknown but probably significant error in the measured values. it is possible that grout moisture changes may be distorting the moisture content measurements of the rock adjacent to the grout column.

The results generally corroborated our concepiual understanding of hydrothermal flow as well as most of the numerical modeling conducted for this study. Locations above the heater showed an initial small increase in liquid saturation as steam generated at locations closer to the heater is displaced radially outwards and condensed. As boiling proceeded, this zone of slightly increased saturation was displaced furthe; out into the rock. The drying front penetrated further into the rock along fractures during full-power heating and the first half of the heater power ramp-down. Fractures were also associated with an enhanced rate of re-wetting (relative to unfractured regions) during the second halt of the ramp down and cool down. Plots of moisture content versus radial distance show that changes during drying and re-wetting were not radially symmetric about the heater axis.

Conceptual models have been developed in conjunction with the nunnerical model calculations to explain differences in the drying and re-wetting behavior above and below the heater. In general. water vapor generated in matrix blocks moved towards the closest fracture or the heater borehole. Upon reaching a fracture, most water vapor moved radially outward through the fracture network until it conde,?sed. Water which condensed above the heater arained downward through tractures back towards the boiling zone and was subsequently re-boiled. The boiling zone effectively provided an umbrella, shielding the underlying rock from this downward flow of condensed water. Water which condensed below the heater drained downward through fractures, away from the boiling zone. Because matrix imbibition was slow relative to the flux of condensed watar through fractures, fracture flow carried this water away
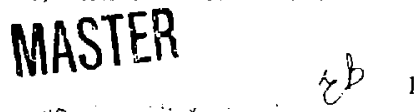
flux of condensed water through fractures, fracture flow carried this water away before matrix imbibition sould detectably increase matrix moisture content below the boiling zone. Numerical modeling indicated that the re-wetting of the dried-out zone was dominated by the binary diffusion of water vapor through fractures. Saturation gradients in the rock matrix resulted in relative numidity gradierts which drove water vapor (primarily along fractures) back to the driedout zone where it condensed along the fracture walls and was imbibed by the matrix.

\section{Introduction}

The Engineered Barrier System Field Tests (EBSFT) will be conducted in the Exploratory Shaft facility at Yucca Mountain to provide information needed for waste package design and pertormance assessments required for license application. Information obtained will help defiite unperturbed environmental conditions in rock within a few tens of meters of the waste packages as well as the perturbations to those conditions caused by the emplacement of nuclear waste. Perhaps the most challenging aspect of waste package performance assessment is that, given only a few years of in situ testing, the hydrothermal response of the near-field must be sufficiently understood (and represented in numerical models) to allow performance to be reliably predicted for 10,000 years. The design strategy relies on limited liquid water contact with the waste package during the first 1000 years after emplacement. Water that might subsequently contact the waste package must be characterized chemically, and preferably will be benign and compatible with the waste form release rate investigations that have been done.

The environmental conditions of concern for the waste package include the conditions existing during the heating phase (when rock temperatures increase after the waste is empiaced), and those in the subsequent cool-down phase resulting from the gradual decay of radioactivity. Therefore, the studies of the environmental conditions need to consider (1) the heating of the rock mass adjacent to the waste packages and the resulting perturbation on the environment and (2) the cooling of that same rock mass with its subsequent rewetting of the dried-out rock mass and readjustment of the rock mass deformations.

The Engineered Barrier System must be appropriately designed (and its performance assessed) to meet performance objectives during two major periods. During the first 1000 years after emplacement substantially complete containment of radionuclides must be demonstrated. The strategy for providing a design that can be shown to meet the performance objectives during this period relies on the unsaturated conditions of the site to limit contact by liquid water with the waste package. During the first 100 years, the temperatures of individual waste packages and associated boreho!es are expected to be above the boiling point which would not ailow liquid water to contact waste package containers. If this expected hydrothermal behavioi can be confirmed, then performance objectives can be met and demonstrated for the first 100 years because container degradation modes invoive contact by liquid water.

From 100 to $10 \mathrm{co}$ years after emplacement, rock mass temperatures are expected to orop, and liquid water might be able to return to the vicinity of 
emplacement boreholes. Whether or not this return will take place, and at what rate, are open questions requiring an understanding of hydrothermal flow for resolution. Temperature response cannot be decoupled from fluid movement. The return of water may be expected to devalop slowly under actual repository conditions. However, it will only be possible in the time available for testing before license application to monitor this process under accelerated time scales. It is very important to monitor trends in the migration of water so that projections can be made of the response under actual repository time scales.

\section{Prototype Testing}

A Prototype Engineered Barnier System Field Test (PEBSFT) was performed in G-Tunnel, which is located within the Nevada Test Site (NTS). The G-Tunnel is physically removed from Yucca Mountain and is in the Grouse Canyon tuft rather than the Topopah Springs tutf. However, welded tut's with properties believed to be similar to tuffis in Yucca Mountain are located in a portion of $G$ Tunnel (Zimmerman and Finley, 1986). Prototyoe testing was initiated so that when the EBSFT is performed, the techniques, instrumentation, and procedures will provide the information needed to characterize the waste package environment. The prototype test was designed to duplicate, to the extent possible, anticipated test conditions for EBSFT at Yucca Mountain; for this, the reader is referred to a paper by Yow (1985), in which the general concepts of a waste package environment test are described. Although the concept for these tests has evolved with time, the overall concept of what we will be measuring and why remains largely as described by Yow.

\section{Anticipated Hydrologic Environment}

The near-field hydrothermal response to thermal loading is shown schematically in Fig. 1. This concept is supported by the experimental work of Caily and others (1986) as well as the numerical modeling of Buscheck and Nitao (1988) and Nitao (1988). The primary mechanisms of heat and fluid flow are depicted for an idealized example of a horizontal heater which is intersected by a near vertical fracture. The actual he 3ter borehole was intersected by more than a dozen iractures. The rock mass consists of matrix blocks which are bounded by fractures and the borehole wall (for blocks immediately adjacent to the heater). Under ambient conditions the matrix blocks are partially saturated and the fractures and torehole are essentially dry. The heater heats the borehole surface primarily via thermal radiation. As heat is conducted through the fractured rock mass, vaporization begins in matrix blocks closest to the heater borehole and then moving on to blocks farther from the heater. Within individual matrix blocks, vaporization proceeds from outer surfaces of each matrix block in towards its center. Where temperatures are in 
excess of saturation conditions, vigorous boiling occurs. In order for water vapor to flow out of the matrix blocks gas-phase pressures must increase from matrix block surfaces to their interiors, resulting in the elevation of the boiling temperature with distance into the matnx block. Water vapor which enters the fractures is subsequently driven by gas pressure gradients (including buoyancy effects) within the fracture network. In general, vapor flow in the fractures is directed away from the center of boiling, either radially outwards or inwards towards the heater hole. Vapor flow in the fractures will parsist until condensation conditions are encountered. Condensed water in the fractures which is not immediately imbibed by the matrix flows under gravity and capillary forces in the fractures either (I) back towards the boiling zone where it re boils or (2) out into the condensation zone where it eventually is completely imbibed by the matrix. The width of the condensation zone is partly dependent on the mobility of the liquid within the fracture. Liquid mobility in the fracture is affected by the ratio of the volumetric liquid flux of water in the fracture divided by the product of the unsaturated porosity and the imbibition diffusivity of the matrix (Nitao and Buscheck, 1989).

\section{Test Concept and Borehole Configuration}

An underground facility called the G-Tunnel Underground Facility (GTUF) has been constructed by the Sandia National Laboratories for the Yucca Mountain Project (YMP). The prototype test was conducted in the Small Diameter Heater Alcove and the Rock Mechanics dritts. The test measured several parameters as a function of location and time in the near field (within a few meters) of a heater placed in welded tuff. The test included an accelerated thermal cycle to examine the effects of the heating and cooling sides of a thermal pulse.

Figure 2 shows the thermal loading history for the test. The initial thermal loading for the $3-\mathrm{m}(9.8-\mathrm{ft})$ heater is approximately $3.3 \mathrm{~kW}(1.1 \mathrm{~kW} / \mathrm{m})$. This initial loading is higher than the loading expected for the spent fuel canister $(0.4$ to $0.7 \mathrm{~kW} / \mathrm{m}$ ) in order to increase the volume of rock disturbed in the relatively short period available for prototype testing and to create sufficiently high rock temperatures to result in boiling conditions. The duration of heating was chosen so that the boiling point isotherm would extend approximately $0.6-0.7 \mathrm{~m}$ $(2.0-2.3 \mathrm{ft}$.$) from the heater borehole wall. This provided a sufficiently large$ volume to include several fractures.

This prototype test consisted of four measurement phases:

1. The ambient temperature phase consists of the measurement of base line conditions prior to heating.

2. The maximum power phase consisted of heating the rock according to She flat portion of thermal loading history shown in Fig. 2. This phase began when the heater was energized on September 7, 1988 at approximately 11:30 a. m. (day 0 on Figure 2).

3. The power ramp-down phase started after approximately 4 months oi heating at maximum power. This phase involves a siepped heater-rampdown period lasting about 10 weeks. 
4. The post-heating phase involved monitoring the rock mass for a few months after the heater was de-energized.

Figures 3 through 5 show the borehole layout and the measurement stations for the geophysical surveys described here. The test location within G-Tunnel is bounded by the Small Diameter Heater Alcove and the Rock Mechanics Incline, as shown in Fig. 3.

The heater borehole is inclined slightly upward (elevation increases from the collar to the end of the borehole) from the Rock Mechanics Incline. as shown in Fig. 5. The diameter of the heater borehole is 12 in. $(30.5 \mathrm{~cm})$.

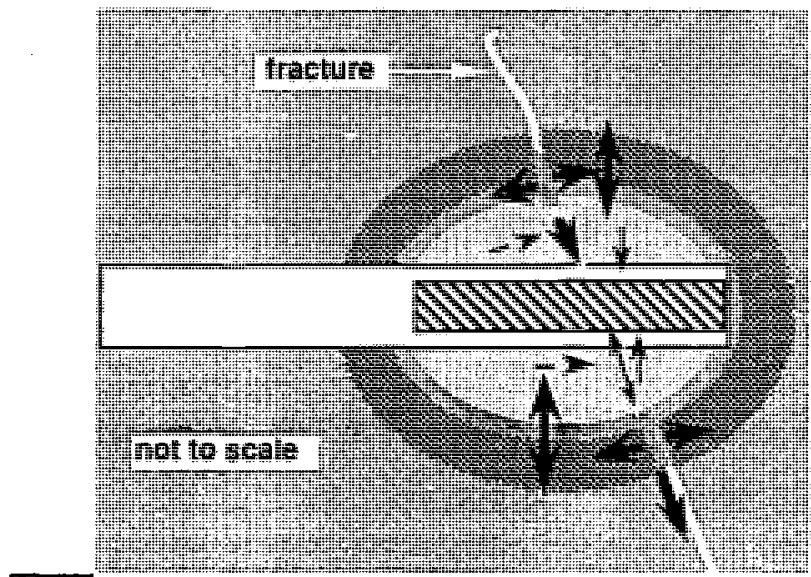

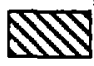

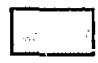

\section{Drier rock}

Wetter rock

\section{Rock at ambient conditions}

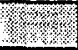

Condensation

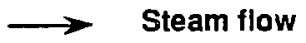

Water flow

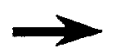

Water flow 
The majority of the boreholes were orthogonal to the emplacement hole axis, which provides better coverage of spatial variations radial to the emplacement borehole. This arrangement allowed measurements in the general direction of expected maximum thermal and hydrologic gradients. Three boreholes were drilled parallel to the heater borehole axis to monitor rock response beyond the ends of the heater.

In boreholes NE-1, NE-2A, NE-3, NE-4, NE-5, NE-6, and NE-7 we used neutron probe measurements to monitor changes in moisture content. Thise measurements were supplemented by gamma-gamma density surveys to detect the slight variations in bulk density caused by changes in moisture content. Other boreholes contained thermocouple psychrometers and microwave resonators to measure air humidity, pressure sensors to measure rock gas pressures, and thermocouples to measure rock mass temperature.

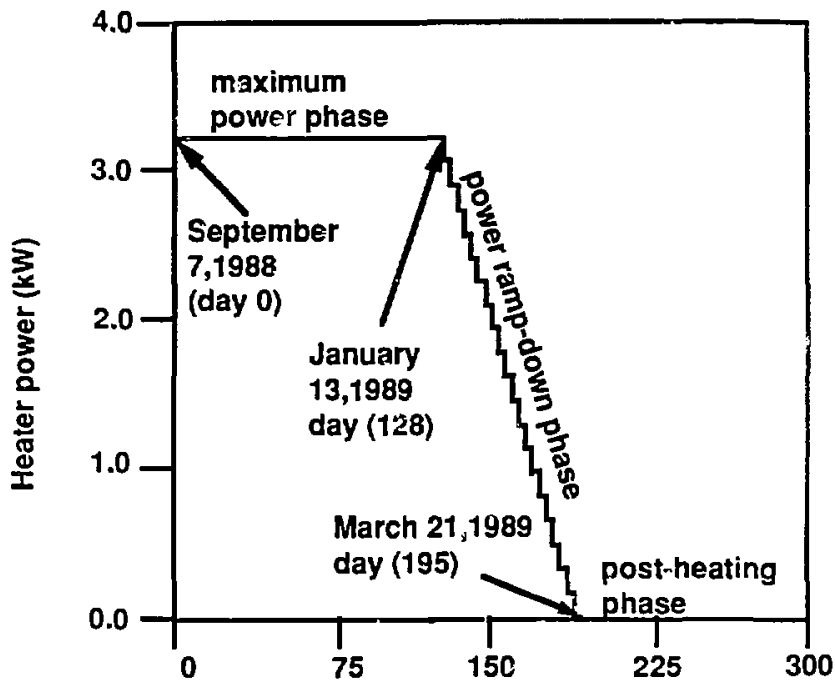

Days

Figure 2. Thermal loading history for the test. 


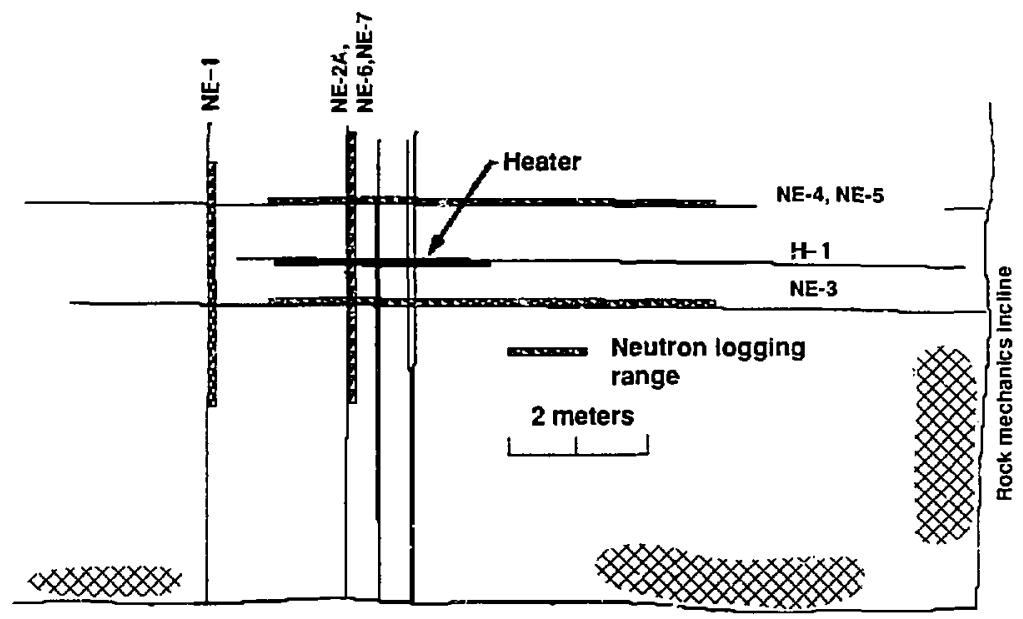

Small dlameter heater alcova

Figure 3. Plan view of the as-built borehole layout. Aiso shown are the ranges of depih sampled by the neutron surveys performed during the test.

\section{Experimental Procedure}

\section{Data Collection}

A neutron logging p:obe is one of the measurement systems being used to detect changes in rock moisture content. The probe contains a source of highenergy neutrons and a detector for slow (thermal) neutrons. The hydrogen present in the water in the rock slows down the neutrons for detection. Seven boreholes (NE-1 to NE-7) were sampled before the heater was turned on; the measurements were repeated after the heater was energized to monitor temporal and spatial changes in moisture ciontent. Measurements were made with the probe stationary for 16 seconds during each measurement every $10 \mathrm{~cm}$ (3.9 in.) along radial boreholes NE-1, NE-2A, NE-6, and NE-7; along the parallel boreholes NE-3, NE-4, and NE-5, measurements were made every 20 $\mathrm{cm}$ (7.9 in.)(Figs. 3, 4, and 5 show the measurement locations). A paraftin shield included with the probe was sampled at the beginning and end of each logging day to verify that the tool was functioning properly and to check and correct for slow drift in counting efficiency. 


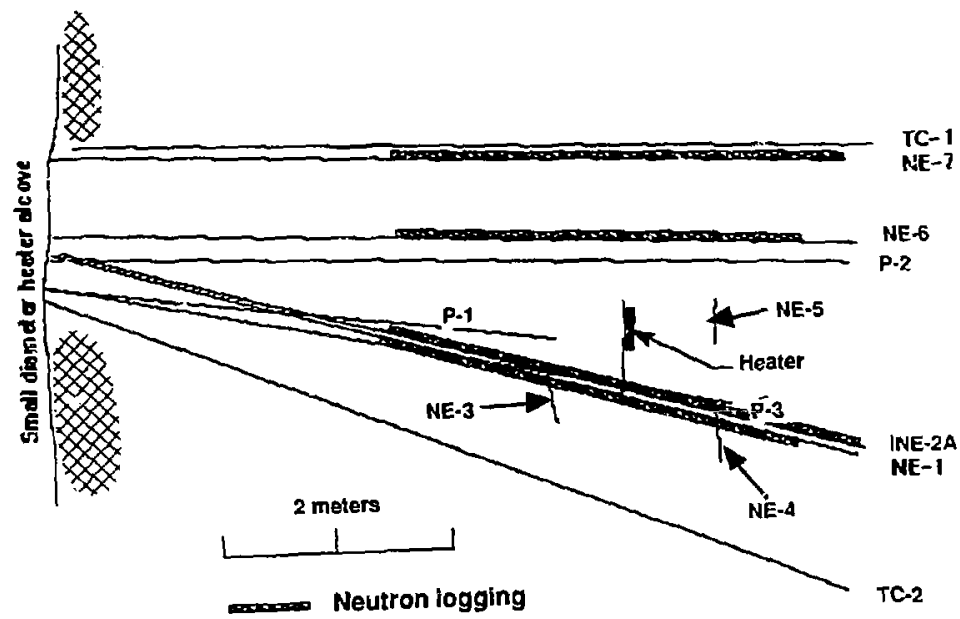

Figure 4 Side view of the as-built borehole layout as observed from the Rock Mechanics incline. Also shown are the ranges of depth sampled by the neutron surveys pertormed during the test.

\section{Probe Description}

The neutron probe used to measure the data presented below is a thermal neutron device manufactured by Campbell Pacific Nuclear CPN (model 503DP) The probe is designed to measure subsurtace moisture by use of a source of high energy neutrons. The cliameter of the sampling volume for the tool is approximately $15 \mathrm{~cm}$ under ambient moisture content conditions. As the rock dries out, this sampling volume increases because there is less water to slow the neutrons. The probe uses a single detector; thus, measurements are sensitive to the presence of elements such as chlorine and boron with large neutron capture cross-sections. The alemental composition of the rock/water system measured in this study is unknown. We have assumed that the pre-test composition did not change signilicantly during the test; thus, the changes in moisture content to be presented in later sections are assumed to be unaftected by changes in elemental composition. This assumption requires further investigation in a future study; the evaporation/condensation cycle may have changed the elemental composition of the water. 


\section{Borehole Construction}

The boreholes surveyed with this tool were constructed as shown in Figure 6 . This figure shows the case for those boreholes to be $7.6 \mathrm{~cm}$ diameter (NE-1. NE-2A, NE-6, NE-7): other boreholes were drilled to a $6.1 \mathrm{~cm}$ diameter and cased with a liner having an O. D. of $4.45 \mathrm{~cm}$ (NE-3, NE-4, NE-5). Note that a grout annulus and liner were used to seal the boreholes so that steam and liquid fiow along the boreholes was minimized. The presence of the liner/grout system probably had an effect on the measured values of absolute moisture content.

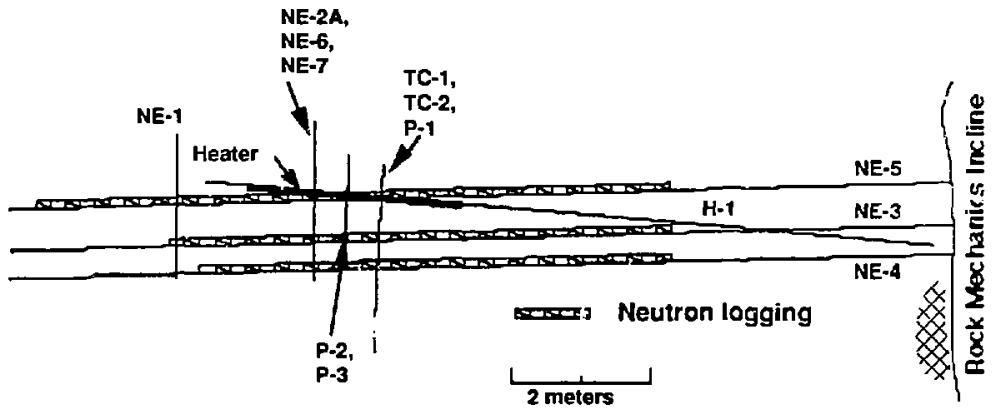

Figure 5. Side view of the as-built borehole layout as observed trom the Small Diameter Heater Alcove. Also shown are the ranges of depth sampled by the neutron surveys performed during the test.

There are no data availaole to estimate this effect. Therefore, we have chosen to present the data as changes in moisture content rather as absolute values. This should eliminate the effects of constant sources of hydrogen such as the liner material; however, the grout (pre-heating) contained water trapped in its pore space as well as water of hydration which probably changed as a result of the heat imposed. In the discussions that follow, it is assumed that the changes in grout moisture content more or less parallel the moisture content chang=s of the rock. We recognize that changes in grout moisture content ditferent from that of the immediately adjacent rock will imfact the measured values, but in a qualitative sense, wo expect the measured vaiues to be representative of the moisture content of the rock mass. This not a severe limitation given that the data will only be used to propose mechanisms for fluid flow which explain the observations; we will not attempt to use the measurements presented here to quantify these mechanisms. Furthermore, for the sampling conditio.ss shown in Figure 6 and assuming a spherical volume of investigation with a diameter of 15 $\mathrm{cm}$, it can be shown that approximately $70 \%$ of the sampled volume consists of 
welded tuff; for the $6.1 \mathrm{~cm}$ boreholes, approximately $85 \%$ of the sampled volume corisists of welded tuit. This suggests that the our expectation that measured values qualitatively represent the rock moisture content is reasonable.

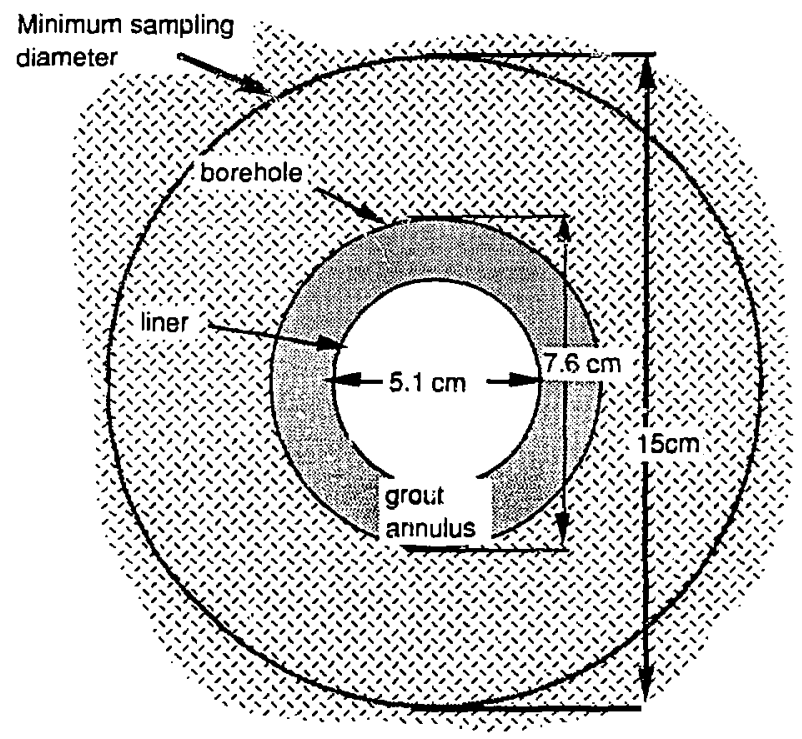

Figure 6. Details of borehole (7.6 cm diameter) construction compared to the sampling volume of the probe. Note that a portion $\rightarrow$ the sampled region is filied with a portland cernent grout.

\section{Data Reduction}

For each borehole, we calculated the differences in water content between the "before" and "after" measurements ("after" heating minus "before" heatir. 3) to produce a difference lug. We chose to use differences rather than absolute values of moisture content hecause we could not account for the effects of the borehole liners and grout within the survey boreholes. To account for these effects, a calibration exercise woula have to be performed using the same liner, grout mix, hole sizes and core present in the field. However, because the changes in moisture content probably parallel ihe changes in the surrounding rock mass, we propose that a difference log should reflect changes in rock mass moisture content in a qualitative sense. In a later section we will attempt to estimate the effect of the grout/liner system on the measured values. 
For a counting time of 16 seconds, the number of counts is approximately 9000 (typical of measurements before heating); assuming that a Poisson's distribution describes the counting process (measurements made at a stationary point provided experimental confirmation that assumption is valid), we estimate that the precision of a single measurement (two standard deviations contidence level) is $\pm 0.0042 \mathrm{~g}$ of water per $\mathrm{cm}^{3}$ (or equivalently Megagrams per cubic meter, $\mathrm{Mg} / \mathrm{m}^{3}$ ). This number multiplied by $\sqrt{2}$ gives us an estimate of the precision in a difference trace of $\pm 0.006 \mathrm{Mg} / \mathrm{m}^{3}$.

A spatial filter was appliod to each difierence log to smooth the spikes in the trace and further improve precision. This spatial filter calculaies a weighted average for each depth location using 5 points (i.e., the measurement miade at the depth of interest and the two measurernents on either side of it). The formula describing this filter is as follows:

$$
W=w 1^{*} F(n-2)+w 2^{*} F(n-1)+w 3^{*} F(n)+w 2^{*} F(n+1)+w 1^{*} F(n+2)
$$

where:

$w=\begin{aligned} & w \\ & n\end{aligned}=\begin{aligned} & \text { the weighted average at the location of interest, } \\ & \text { index value in the array of measurements for the location }\end{aligned}$
$F=0.1$ (arbitrarily chosen weight),
$w_{1}=0.2$ (arbitrarily chosen weight), and
w2 $=0.4$ (arbitrarily chosen weight).

Each difference trace was smoothed using this tilter to enhance spatial and temporal trends in the data and to improve the precision of each difference trace. The precision estirnate for the filtered points is \pm 0.003 . Filtering improves the precision of the data by a factor of 1.96 over the unfiltered data. This precision estimate means that for any one point on a difference trace that equals or exceeds \pm 0.003 , there is a $5 \%$ probability that it is caused by random fluctuations, rather than reflecting a true change in the measurement

We can also look at an ensemble of points along a difference trace to define a trend (i.e., above or below zero). For an n-point average of data points which exhibit randorn, uncorrelated variation, the precision of the mean is smaller than the precision of the individual points by a factor of the square root of $n$. Thus, assuming the variation in our unfiltered data points is uncorrelated, the expecteci variation of a 16-point ensemble of them would be $( \pm 0.006) / 4$ or $\pm 0.0015 \mathrm{Mg} / \mathrm{m}^{3}$.

To estimate the precision of an n-point ensemble of already fittered (and thus correlated) points, we can conside! the effect of a two part process, filtering and averaging, on the unfiltered data. That process improves the precision of the unfiltered data by a factor $n /(n-1.96)^{0.5}$, or, for $n=16,4.27$. Thus, the error estimate for a i6-point ensemble of filtered data points would be $\pm 0.006 / 4.27$ or $\pm 0.0014 \mathrm{Mg} / \mathrm{m}^{3}$; for 32 points, it would be $\pm 0.006 / 5.84$ or $\pm 0.0011 \mathrm{Mg} / \mathrm{m}^{3}$. However, note that each day's data is interpreted as a ratio to a standard count (STD) made at the beginning and/or end of the day. The standard count 
consists of 32, 8- second counts in a fixed environment that produces about 8000 counts in 16 seconds, so the precision $0^{x}$ the STD is a factor of four better than a single data point, or, in terms of water content, $\pm 0.001 \mathrm{Mg} / \mathrm{m}^{3}$.

In the interpretation that follows, we will define ensemble trends (where possible) to establish whather a statistically significant change has occurred along a borehole at a particular time and to determine the sense (i.e., increase or decrease) of the change. Based on these trends, we will infer whether the amount of liquid water around the borehole has increased or decreased relative to preheating conditions or relative to the last day of the heating phase.

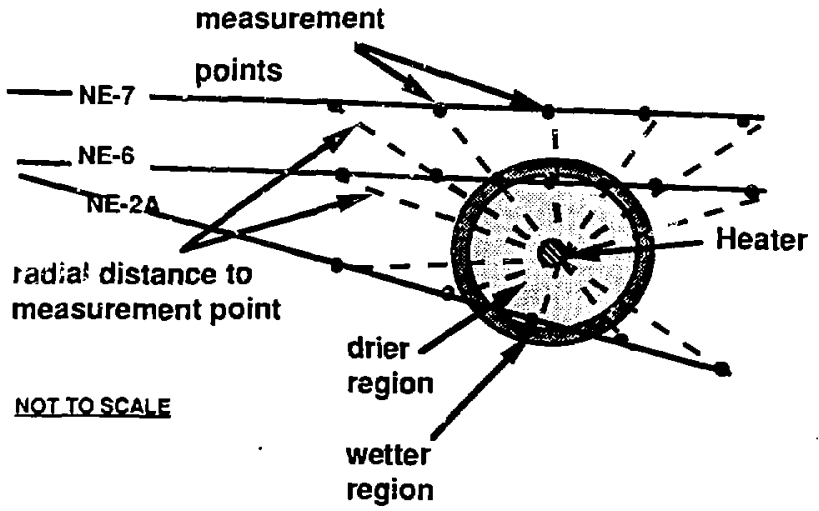

Figuie 7. Data collected along three coplanar boreholes near the middle of the heater (boreholes INE-2A, NE-6 and NE-7) can be plotted as a function of radial distance as illustra! ad above.

\section{Besults and viscussion}

\section{Radial profiles of changes in moisture content}

Boreholes NE-2A, NE-6 and NE-7 are three coplanar boreholes located near thn center of the heater as shown in Figures 3 and 4 . The data collected along these boreholes can be combined and plotted as a function of radial distance to the center point of the heater assembly (see Figure 7). Figures 8 through 12 show radial profiles of changes in moisture content during various stages of the test. Note that these radial profiles are not composed with data collected along a single radial traverse; instead the profiles represent borehole traverses that sampled many different radial distances along a non-radial route. The changes to be shown were calculated relative to pre-heating moisture measurements. Each figure consists of two plots which show the same data at two different 
scales so that the smaller changes which occur at the more distant locations can be cbserved. These radial profiles are used to evaluate the degree of redial symmetry for moisture distribution around the heater.

Figure 8 shows a radial profile of moisture content change five days after the heater was energized. The changes detected at this time are smaller than the precision estimate of $+/-.003 \mathrm{Mg} / \mathrm{m}^{3}$ for an individual filtered difference as described previously. An ensemble of points can be identified for all the points in boieholes NE- 6 and NE-7, and a second ensemble can be identified for borehole NE-2A. The ensemble average for the 69 points in the NE-6/NE:-7 ensemble is 0.002 . The precision estimate for this ensemble average is . $+\%$ $006 / 8.427$ or $+/-0.0007$. This means that there is a less than a $5 \%$ probability that the increase in moisture content reflected by the ensemble average $(0.002)$ could be caused by random fluctuations. In other words, the points within the ensemble show a small but statisticaily significan: increase in moisture content. Note that the points in the ensemble are from boreholes NE- 6 and NE-7 located above the heater. A similar ensemble can be identified for data collected along NE-2A (majority of measurement points have lower elevations than the heatar). The average for the 35 points in the NE-2A ensemble is -0.001 . The precision estimate is $0.006 / 6.089$ or $+/-0.001$. This means that there is a $5 \%$ probability that the measured changes could be caused by random iluctuaticns; therefore the decreases in moisture content along NE-2A are likely to represent valid changes in moisture content. Thase estimates provide strong indication that the measuren values probably represent true changes in the rock.

Sunımarizing, the rock ahove the heater showed a small increase in moisture content after five days oi heating whereas the rock below the heater showed a small decrease. This may be due to several factors:

1) The hotter temperatures measured on top of the heater container (Lee and Ueng, 1989) may have caused more evaporation and condensation above the region at this time. 2) The rock below the heater was wetter (Daily and others. 1989) and may be have been close to full saturation when the test started and could noi gained much more water. 3) The buoyancy of the hot vapor phase may have resulted in more vapor flow upward than downward. It may also be due to the way steam condensate drains in the fractures; once condensate forms in the fractures, water will start draining verticali; downward. Note in Figure 1 that, for the steam flow and condensate ilow directions shown, th.e upward penetration of the diry region will bo retarded by the condensate that drains back to the boiling zone. Below the haater, the dry region can penetrate more because the condensate drains away from the boiling region.

Figure 9 shows a radial profile of moisture content change seventy days after the heater was energized These data were ccilected near the mid-point of the maximum power phase of the test. As expected, the rock closest to the heater is losing substantial amounts of moisture. However, the rock near borehole NE$2 \mathrm{~A}$ is drying at a faster rate than the rock near NE-6. A.s explained above, condensate above the heater will drain towards the boiling region whereas below the heater it will drain away; this can explain the differences in the penetration of the drying front. 


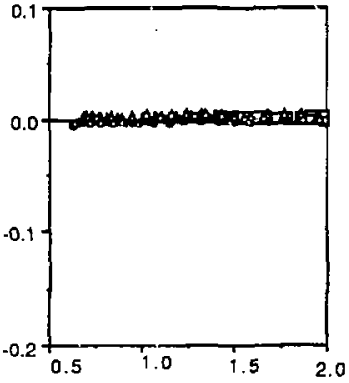

radiai distance $(\mathbf{m})$

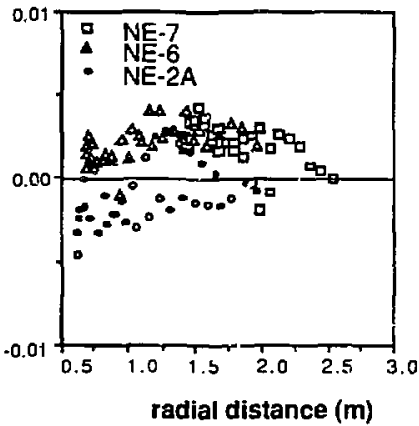

Figure 8 Changes in moisture content piotted against radial distance after 5 days of heating ( very early maximum power phase). Changes are calculated relative to pre-heating moisture conditions. Note the exaggerated scale on the the right hand figure showing smaller changes occurring at longer distances.

Figure 10 shows a radial profile of moisture content change (from initial conditions) 127 days after the heater was energized. These data were collected durirg the last day of the maximum power phase of the test. Note that the NE2A profile shows very little additional drying when compared to Figure 9 while the NE-6 profile shows signiticant additional drying. Both profiles in Figure 10 are now closely matched with the caveat that the width of the drying region appears to be slightly wider near NE-2A. The slosely matched protiles suggest that the rock near NE-2A and NE- 6 is almost completely dry. Also, very little additional drying occurred near NE-2A (at radiai distances less than $0.75 \mathrm{~m}$ ) during the last 57 days while the heater continued operating at constant power. Note that the radius of the dry zone achievad is approximately $0.7 \mathrm{~m}$; this is consistent with the test objective of achieving boiling conditions within a 0.6-0.7 $\mathrm{m}$ radius.

Figure 10 shows that a few points located batween 1.75 and $2.25 \mathrm{~m}$ radil show an increased moisture content. Note that these changes are smaller that the precision estimate of $+1.0 .003 \mathrm{Mg} / \mathrm{m}^{3}$. This means that the wetting halo postulated in the Introduction is largely undetectable. This may be an indication that the rate of imbibition for the condensate is slow relative to the velocity of liquid water draining down the fractures. Alternatively, it may mean that the pre-test rock saturation was near $100 \%$ (probably due in part to drilling water imbibition); therelore, the rock could only gain very modesi amounts of additional water. 

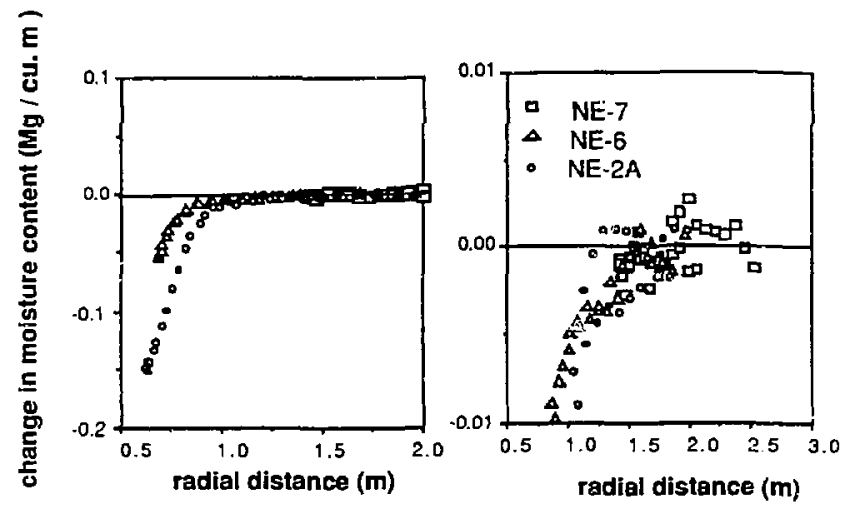

Figure 9. Changes in moisture content plotted against radial distance after 70 days of heating (approximately micway through the maximum power phase). Changes are calculated relative to pre-heating moisture conditions. Note the exaggerated scale on the the right hand figure showing smaller changes occurring at longer distances.

The data from NE-2A in Figure 10 show that, at radial distances less than 0.75 $m$, the rock appears to have dried almost completely. This result can be used to establish a lower bound on the effect of the grout column on the changes in moisture content, if the porosity of the rock is known. Porosity measurements from 25 core samples taken around the test region indicate that the aver ige porosity is $12.8 \%$ with a standard deviation of $+1-2.3 \%$ (Lin, 1990). Supposing that the pre-test saturation of the rock was around $100 \%$, this would mean that the maximum change in moisture expected if the rick dried completely is 12.8 volume $\%$ or $0.128 \mathrm{Mg} / \mathrm{m}^{3}$. The NE-2A data at distances less than $0.75 \mathrm{~m}$ shows a change in moisture content of $0.16 \mathrm{Mg} / \mathrm{m}^{3}$. (or 16 volume \%). This means that the grout column may have added, as a minimum, approximately 3 volume $\%$ to the changes that could be attributed to the rock. If the initial saturation of the rock mass were less than $100 \%$ (it probably was because the site is above the water talie? and the boreholes were essentially dry), then the effect due to the grout would have to be larger. It is clear that for future investigations, the changes in moisture content of the grolit column need to be characterized, so that corrections can be made to the measured values. 


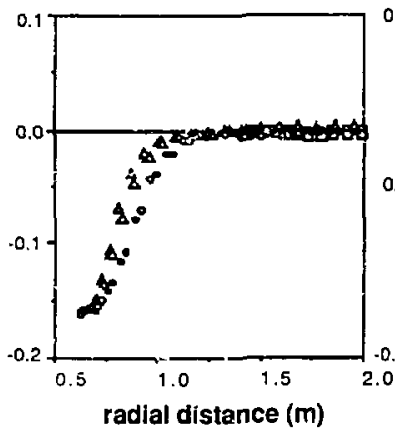

$$
\begin{array}{ll}
001 & \text { NE-7 } \\
\triangle & \text { NE-6 } \\
\text { NE-2A }
\end{array}
$$

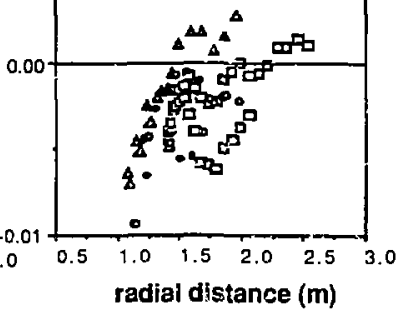

Figure 10. Changes in moisture content plotted against radial distance for the last day of full power heating. Changes are caiculated relative to pre-heating moisture conditions. Note the exaggerated scale on the the right hand figure showing smaller changes occurring at longer distances.
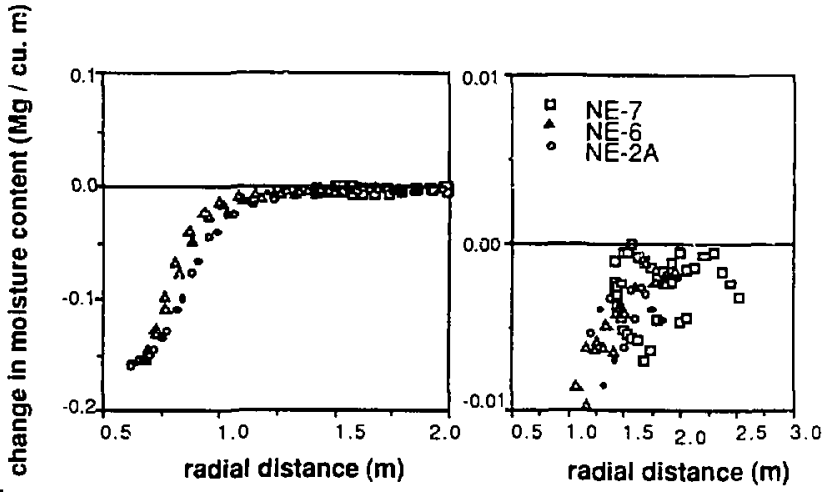

Figure 11. Changes in moisture content plotted against radial distance after 175 days of heating (near the end of the power ramp-down phase). Changes are calculated relative to pre-heating moisture conditions. Note the 
exaggerated scale on the the right hand figure showing smaller changes occurring at longer distances.

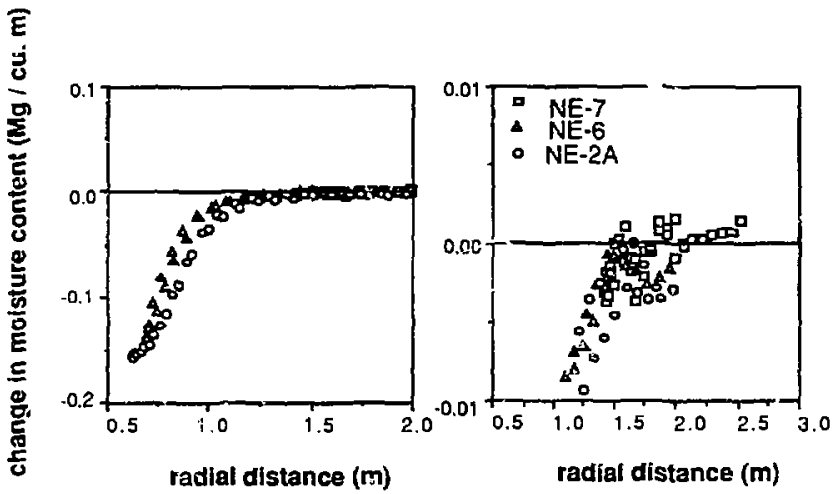

Figure 12 Changes in moisture content plotted against radial distance 237 days after start of heating (45 days after heater was de-energized). Changes are calculated relative to pre-heating moisture conditions. Note the exaggerated scale on the the right hand figure showing smaller changes occuring at longer distances. 

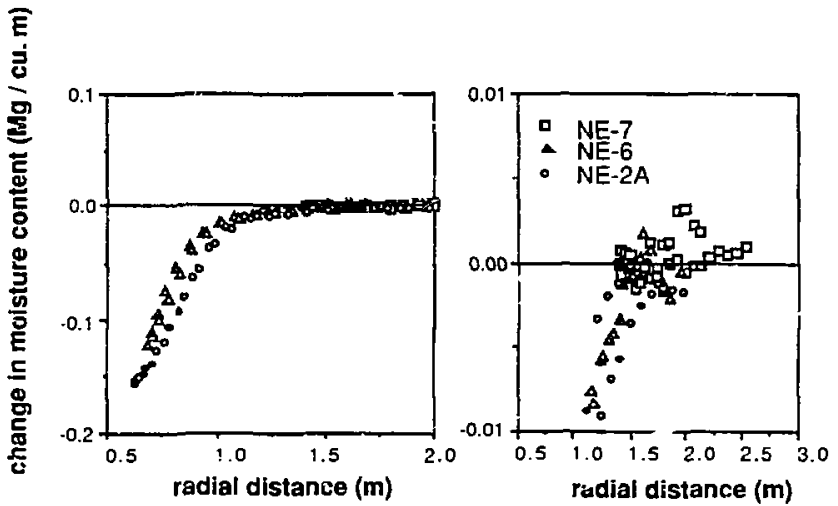

Figure 13. Changes in moisture content plotted against radial distance $30 t$ days after start of heating (106 days aiter heater was de-energized). Changes are calci'ated relative to pre-heating moisture conditions. Note the exaggerated scale on the the right hand figure showing smaller changes occurring at longer distances.

Figures 11,12 and 13 show the changes in moisture content measured during the power ramp-down and post heatirig phases of the test when the temperatures near the heater were decreasing. A comparisc " of Figure 10, 11, and 12 shows that relatively small changes occurred during the power rampdown phase. Figure 13 shows a similar trend with the exception that the section of NE-6 at a radial distance of approximately 0.6 to 0.75 meters (this rock is directly above the heater location) is recovering more moisture than the rock atong NE-2A at the same radial distance. This means that for a given radius from the heater centerline, the rock above the heater is regaining moisture at a relatively faster rate than the rock below the heater. Mechanisms that explain re-wetting behavior are proposed in an upcoming section.

Radlal protiles of moisture content changes relative to the last day of full power heating

Further insights into the re-werting process can be gained by calculating changes in moisture content relative to the last day of full power heating. These plots should only show the changes in moisture content that developed during the ramp-down and post-heating phases of the test. Figure i4 presents radial profiles of changes in moisture where "after" minus "before" changes are calculated relative to day 127 (i.e., the "before" data corresponds to day 127). 
For example, the top plot in Figure 14 was constructed by substracting the data for day 146 from the data for day 127 . Filtering was pertormed as explained previously. The three plots shown correspond to changes early (day 146) and late (day 175) in the power ramp-down phase, and late in the post-heating phase (day 301). Note that the data for day 146 show some additional drying near 0.8-0.9 meters in spite of reductions in heater power; for comparison, maximum heater and heater borehole wall temperatures were achieved on day 128. Late in the ramp-down phase (day 175), boreholes NE-6 and NE-2A show increases in moisture cuntent in the 0.7-1.0 meter region. In the meantime, the rock beyond 1.2 meters siows no detectable change. The data for day 301 provide additional confirmation that the rock beyond $1.2 \mathrm{~m}$ is not changing while the $0.7-1.0$ meter region continues; to gain moisture. 


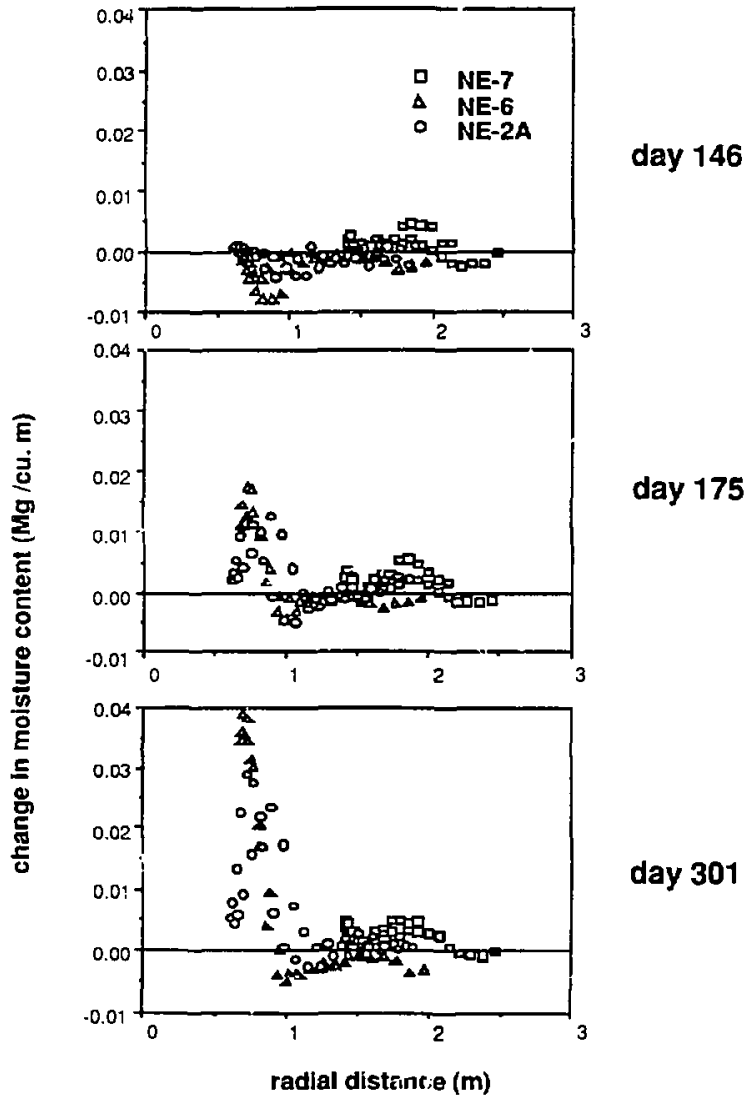

Figure 14. Changes in moisture content plotted against radial distance during the power ramp-down and post heating phases. Changes are calculated relative to the last day of heating at maximum power.

\section{Effects of fractures on moisture content changes during drying}

Fractures affected the hydrothermal environment which developed during the course of the test. The a priori conceptual model shown in Figure 1 shows that fractures were expected to serve as flowpaths for steam, serve as condensation 
points where sufficiently cool iemperatures exist, and may rlso serve as drainage flowpaths for condensate forming in the ccoler regions.

Fractures appear to increase the rate of drying of the rock mass. This can be observed in Figures 15 and 16 where the profiles for moisture content change are compared with fracture locations mapped with a borehole television camera (Ueng and Towse, 1989). Most of the fractures shown do not intercept the heater borehole. Note that regions showing higher degree of drying also occur where fractures are present. This trend is present where the fractures are closer to the heater and near boiling conditions (e.g. the fractures in borehole NE-2A at about $4.8 \mathrm{~m}$ where the temperature is approximately $900 \mathrm{C}$ ); and also in substantially cooler regions farther away from the heater (e.g., the fractures in borehole NE-6 at depths of 3.7 and $5.85 \mathrm{~m}$ where the appruximate temperatures were $44^{\circ}$ and $600 \mathrm{C}$ respectively). It is suggested that fractures tend to dry rock because they act as relatively constant pressure boundaries at approximately ambient pressure. As boiling raises gas pressures in the matrix blocks, vapor will flow towards these constant pressure boun'daries. This depressunzation effect will allow more effective evaporation to occur near fractures relative to unfractured regions. Temperature measurements reported by Lin et al., 1990 indicate that some tractures along borehole P-3 appear to be related to somewhat lower local temperature near the fractures by a few degrees $\mathrm{C}$. The cooler temperatures are due to the fact that higher fracture density results in lower gas pressures required to drive vapor out of the blocks; lower gas pressures result in lower saturation temperatures (i.e. boiling at lower temperature). In regions beyond the boiling front, lower temperatures in mor highly fractured regions are related to the increased latent heat transport whict slows the rise in temperatures.

Similar behavior is shown in Figure 17 which shows profiles of moisture content differences detected in borehole NE-5. This borehole is parallel to and approximately 0.8 meters trom the axis of the heater borehole (refer to borahole layout shown in Figures 3, 4, and 5). Figure 17 also shows fractures mapped along borehole NE-5. The region between depths 7.9 and 8.4 meters is bounded by two fractures and shows enhanced drying. Note that the unfractured rock between 8.75 and 9.9 m lags in drying when compared to the $7.9 \cdot 8.4 \mathrm{~m}$ region which is bounded by two fractures. However, the region between depths 6.9 and $7.8 \mathrm{~m}$ shows a general increase in moisture content. The rock in this region is substantially cooler because it is located off the end of the heater element. It is suggested that the rock in this cooler region may act as condensation (and imbibition) surfaces for steam moving in from hotter parts of the rock; most of the steam is probably moving to this region along fractures due to their higher permeability. Some fractures may also serve as drainage paths which carry condensate downward when sufficient condensate collects at higher elevations along the fracture as suggested by the conceptual model in Figure 1. 


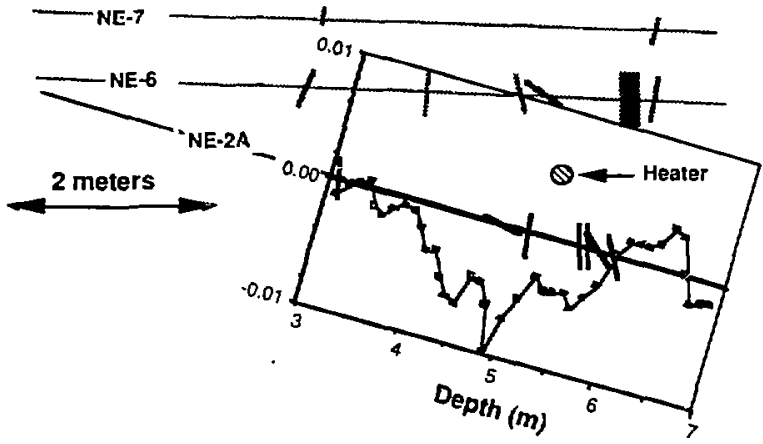

Figure 15. Changes in moisture content for borehole NE-2A, 21 days after the start of heating (early maximum power phase). Fractures mapped along NE-2A are shown for comparison. Also shown are the locations of the heater and of borgholes NE-6 and 7.

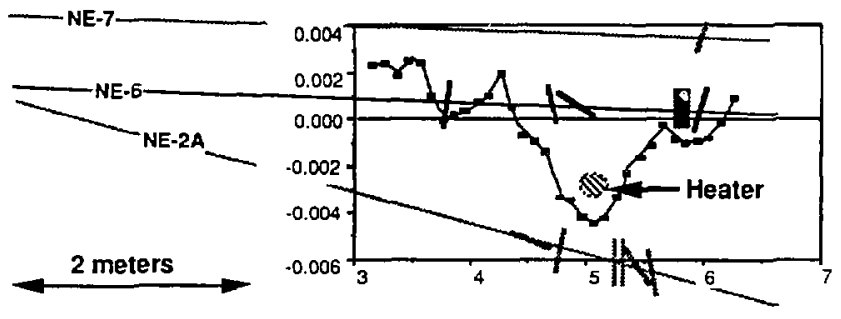

Figure 16. Changes in moisture content for borehole NE-6, 21 days after the stait of heating (early maximum power phase). Fractures mapped along NE- 6 are shown for comparison. Also shown are the locations of the heater and of boreholes NE-2A and 7 . 


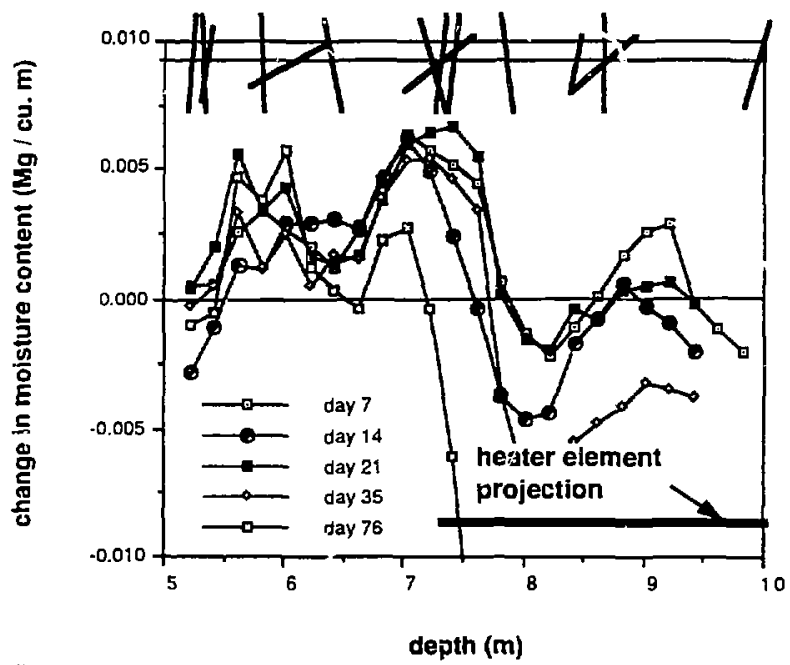

Figure 17. Changes in moisture content mapped along borehole NE-5. Changes are calculated relative to pre-heating conditions. Fractures mapped and the projected location of the heater are shovir for comparison.

Borehole NE-3, located below and to the side of the heater borehole (reter to

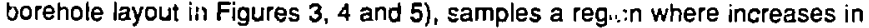
moisture content would be expected if fractures served as drainage paths for condensate. Figure 18 shows the NE-3 results diling the maximum power phase of the test. Changes are calculated relative: to day 6 atter the heater was energized; preheating data cannot be reliably used to calculate differences in this case because of an offset in sampling depths of several centimeters. This means that any changes which occurred during the first 6 days of the test are indeterminate; however, drying changes are likely to be very small because the maximum temperature at the NE-3 location was only 31 or $32^{\circ} \mathrm{C}$ during this time. Furthermore, the curves for days 14 and 21 show that the rock changed very little over a 7 day period during the early stages of heating; this suggests that this portion of the roc: isass was changing very little during the early stages of heating. The NE-3 data show that the rock closest 10 the heater generally dries out with the exception of the region at $9.4 \mathrm{~m}$; data for the $9.4 \mathrm{~m}$ region may be misleading because it coincides with the poirt of interception between NE-3 and another borehole which was grouted shut prior to the start of heating; it is 
prudent to disregard these data. Thus, the rock below the heater shows no evidence of increases in moisture content (if the $9.4 \mathrm{~m}$ data are disregarded). Therefore, there is little direct evidence of condensate drainage through this region trom regions above; however, it is likely that imbibition is very slow compared to the velocity of liquid draining down fractures. Hence, no measurable change in saturation resulted from condensate drainage in this region. Small increases in moisture content were obs aved in the vicinity of $\mathbf{5 . 4}$ $m$ depth. This location approximately coincides with the location of a water drip observed to develop within the heater borehole ater heating started; this circumistantial evidence suggests that the fractures in the $5.4 \mathrm{~m}$ region may havi? served as drainage paths during a portion of the test.

Borehole NE - 4 (figure 19) does show evidence that some of the fractures acted as pathways for condensate drainage. NE-4 is similar to NE - 3 because it is also located below and to the side of the heater axis and is parallel to the azimuth of the heater axis. It is different from NE - 3 in that in NE-4 the distance to the heater axis is app:oximately $1.4 \mathrm{~m}$ while the NE- 3 distance is approximately $1.0 \mathrm{~m}$. Thie $\mathrm{NE}-4$ data show trends similar to the NE - 3 data but the magnitude of the cinanges is substantially smaller. The NE - 4 data show that the region around $9.8-10.0 \mathrm{~m}$ of depth gained moisture during the first 76 days of the test. It also show's that this region zoincides with a region of multiple fractures. Condensate generated above this location is prot)ably draining through these fractures and imbibing into the surrounding matrix.

\section{Effects of fractures on moisture content changes during re-wetting.}

As illustrated by the radial profiles shown in Figures $11,12,13$, and 14, rock near the heater changed relatively little during the power ramp-down and postheating phase of the lest when the rock was cooling and re-wetting. Figure 14 shows that the rock above the heater (borehole NE-6) is re-wetting faster thic : the rock below the heater (borehole NE-2A). One possible explanation for the differing rates of drying and re-wetting above and below the heater is that gravity - driven flow may be playing a role in these processes. Further insights into the re-wetting process can be gained by calculating changes in moisture content relative to the last day , i maximum power heating. Figure 20 presents changes in moisture in borehr ie NE-2A, where "after" minus "before" changes are calculated relative to day 127 (i.e., the "before" data corresponds to day 127-next to last day of the maximum power heating phase of the test). The data were obtained during the power ramp-down and post heating phases of the test when the rock was cooling and re-wetting. Also shown are fractures mitippad along the boreholes. Note that the rock regions that show the largest re-wetting are clustered around the fractures in NE-2A. This is an indication that fractures may play a role in the re-wetting process. 


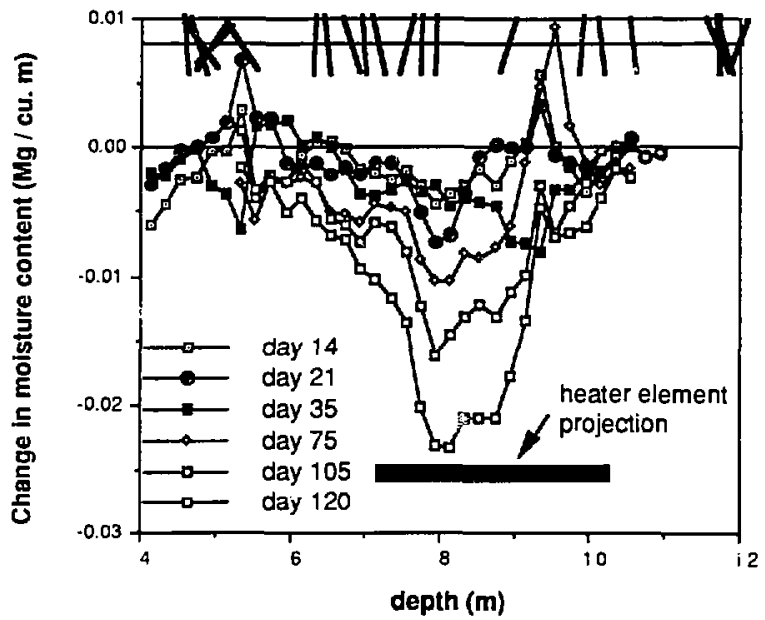

Figure 18. Changes in moisture content mapped along borehole NE-3. Changes are calculated relative to day 6 after the hearer was energized. Fractures mapped and the projected location of the heater are shown for comparison.

Numerical modeling conducted for this study indicates re-wetting behavior may be dominated by the movement of vapor, primarily by binary diffusion, along fractures (Buscheck and Nitao, 1990). Saturation gravients in the rock mass result in reiative humidity gradients which drive water vapor back towards the dried-out zone. As this water vapor reaches the dried-out zone, it condenses along the fracture walls and is imbibed by the matrix. Fractures cominaie the bulk permeability of the rock mass (Lee and Ueng, 1989). Relative to an unfractured rock mass, the presence of fractures (and the very high mobility of vapor driven by birary diffusion) effectively shortens the distance over which water musi be imbibed in order to re-wet the dried-out region.

Another mechanism that may be playing a role in the re-wetting process is water trickling along fractures from more highly saturated zones at higher elevations. Figure 21 shows changes in moisture content for horehole NE-6 relative to the last day of maximum power heating. Figure 21 shows evidence consistent with this argument in that the increases in moisture along fractures above the heater (borehole $\mathrm{AEE}-6$ ) are larger than increases below the heater (NE-2A) measured at the siame time. Marrix flow should be extremely slow given that the permeability of the rock is $1 \times 10^{-6}$ darcies (Lin, 1990) and the pressure head is driven primarily by elevation differences of only 1 to 2 meters. 
Note that the rock near NE-6 has regained approximately $25 \%$ more water than rock near NE-2A. The NE-6 increases in moisture appear to be slightly larger near tractures; however, the NE-6 moisture increases near unfractured regions are much larger than any observed in boreholes NE-2A. This suggests that $r e$ wetting along fractures may be relatively more important below the heater than above. It may be that the dry region around the heater acts as a shiald that intercepts most of the condensate draining downwards from higher regic.ss; in this case, the most significant re-wetting mode would consist of diffusion driven flow of vapor along fractures, condensation along the fracture face, and matrix imbibition.

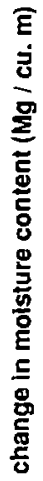

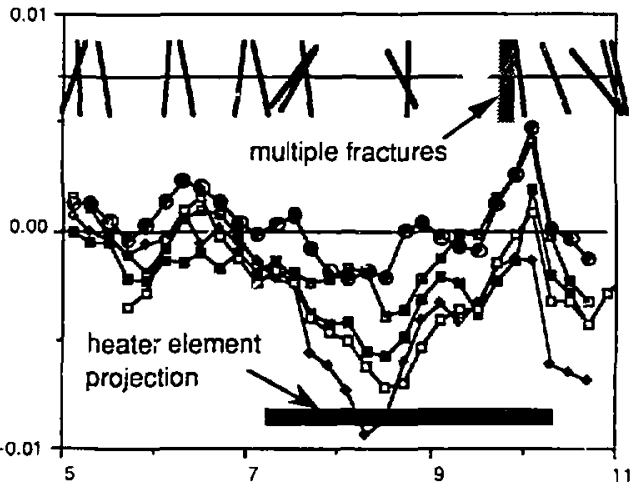

Depth (m)

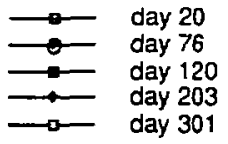

Figure 13. Changes in moisture content mapped along borehole NE-4. Changes are calculated relative to day 6 after the heater was energized. Fractures mapped and the projected location of the heater are shown for comparison. 
Moisture content changes along NE-5 (parallel to the heater and about the same elevation) are shown in Figure 22 for the power ramp-down and post heating phases of the test. This data shows that the rock near NE-5 (radial distance to the heater approximately $0.8 \mathrm{~m}$ ) is behaving in a fashion similar to the rock near NE-6 above the heater as the rock begins to cool and re-wet; i.e., the re-wetting changes may be slightly larger near fractures, but fractures do not appear to dominate the re-wetting process as in the case of NE-2A. The rock at $7.2 \mathrm{ml}$ and $9.5 \mathrm{~m}$ continues to dry even though the heater power is decreasing and temperatures are cooling, probably because these two regions were wetter than the surrounding rock mass when the rock was drying (reter to Figure 17). Also the rock beyond the two ends of the heater appears to be changing very little (changes are very slose to the detection limits), but the changes indicate that the rock is probably losing water. Also, air in fractures in contact with these wetter regions can carry vapor via diflusion driven flow as described earlier.

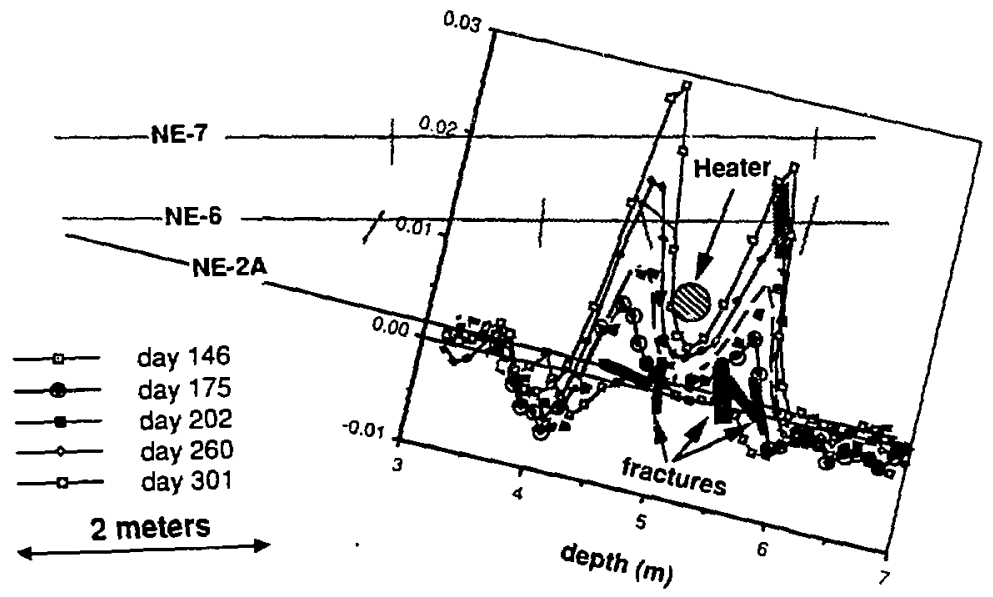

Figure 20. Changes in moisture content mapped along borehole NE-2A. Changes are calculated relative to the last day of maximum power heating. Also shown are the locations of boreholes NE-7, NE-6, fractures mapped along boreholes, and the heater location.

Moisture content changes along NE-3 (parallel to the heater and lower in elevation) are shown in Figure 23 for the power ramp-down and post heating phases of the test. Note that most of the changes are very close to the detection limits. These data show that the rock near NE-3 (radial distance to the heater is roughily $0.9 \mathrm{~m}$ ) behaved differently than the rock near NE-5; these two boreholes are located at simits radial distances from the heater borehole axis. The NE-3 data show that the rock closest to the heater coninued to dry along the 7.2 to $7.8 \mathrm{~m}$ section (albeit slightly) as the rock cooled, and very littie 
evidence of re-wetting (if any) is obsenved. This behavior contrasts with the NE5 behavior closest to the heater (shown in Figure 21) where the rock re-gaired water to a substantial degree. These data corroborate data from NE-2A and NE-6 which showed more re-wetting above the heater than below the heater.

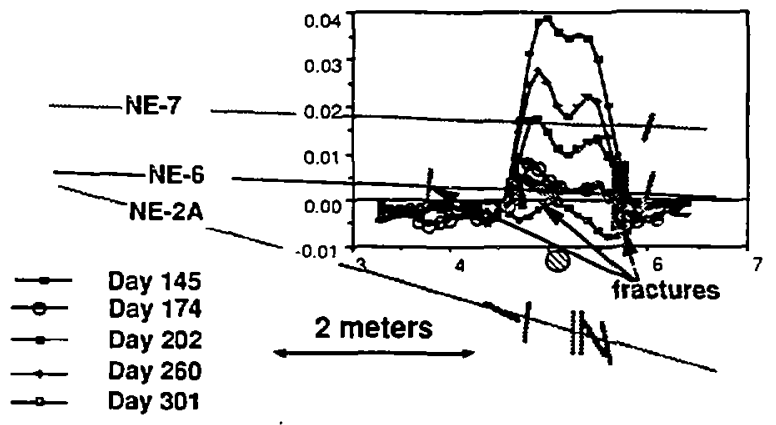

Figure 21. Changes in moisture content mapped along Dorehole $N E-6$. Changes are calculated relative to the last day of maximum power heating. Also shown are the locations of boreholes NE-7, NE-2A, fractures mapped along boreholes, and the heater location.

\section{Molsture content changes as a function of time}

Figure 24 shows how the moisture content changed as a function of time a: three points approximately equidistant $(0.78 \mathrm{~m}$ radially) from the center of the heater. The point above the heater corresponds to borehole NE- 6 , depth 5.35 $\mathrm{m}$; the point to the side of the heater corresponds to NE-5, depth $9.22 \mathrm{~m}$; the point below the heater corresponds to NE-2A, depth $4.49 \mathrm{~m}$. This figure shows inat, for any given time, the rock above and to the side of the heater dried less than the rock below the heater. It also shows that the re-wetting process is slow in relation to the rate of drying. The rate of re-wetting remains approximately constant during the power ramp-down and post-heating (i.e., after heater was turned off) phases of the test as illustrated by the constant slope during this period. Note that during this time period (reter to Figure25) the temperature changes are very large. This suggests that during cooldown, the re-wetting rate was not limited by the rate of retreat of the temperature field; however, in the repository environment it is expected that the re-wetting front will follow the retreat of the temperature field because the re-wetting rates will be last relative to the rate at which temperature will retreat. This difference between the test environment and the expected repository environment is probably caused by the highly accelerated power decay (note that the power ramp down phase shown in Figure 2 lasted c.ily 68 days); this contrasts with the duration of power decay for a true waste package lasting a several centuries. In the test environment, the rates of imbibition and capillary condensation are slow relative 
to the accelerated decrease in temperature; however, in the repository the rates for these processes are fast relative to the rate of temperature decrease.

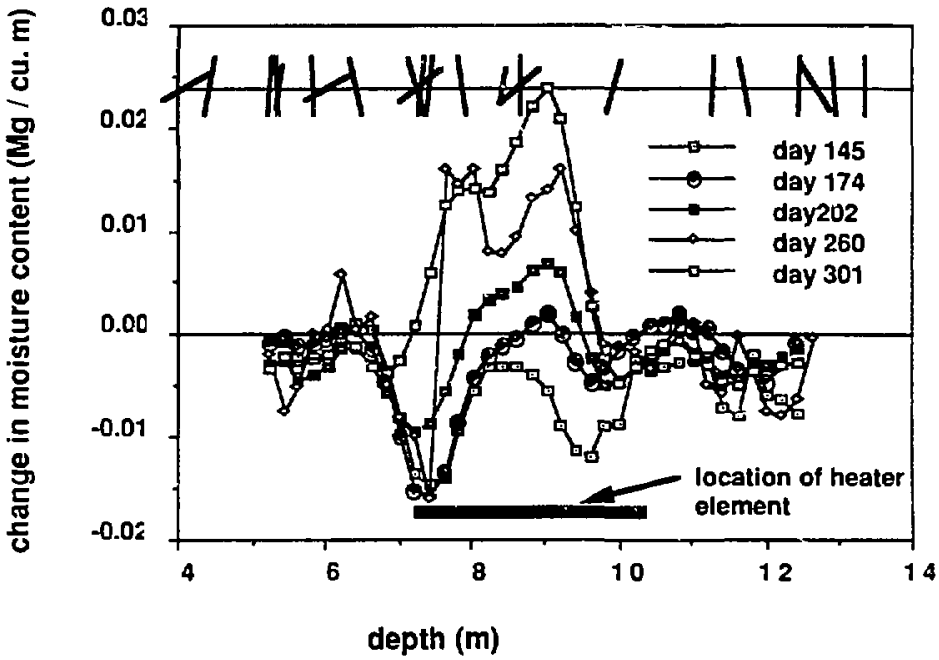

Figure 22. Changes in moisture content mapped along borehole NE-5. Changes are calculated relative to day 120 , one week before the end of maximum power heating. Fractures mapped and the projected location of the heater are shown for comparison. 

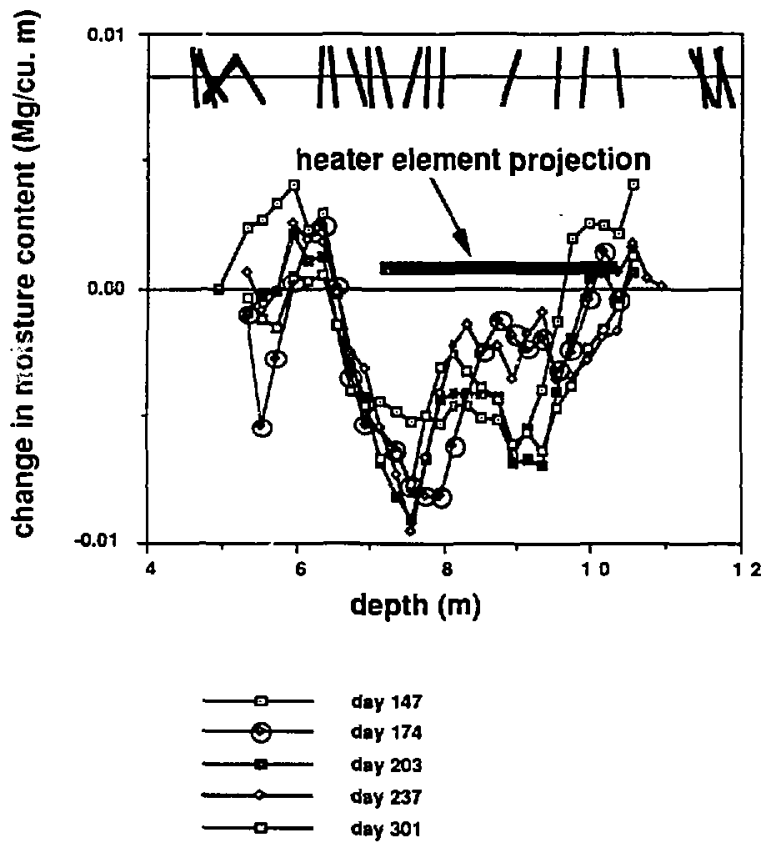

Figure 23. Changes in moisture content mapped along borehole NE-3. Changes are calculated relative to day 120 , one week betore the end of maximum power heating. Fractures mapped and the projected location of the heater are shown for comparison. 


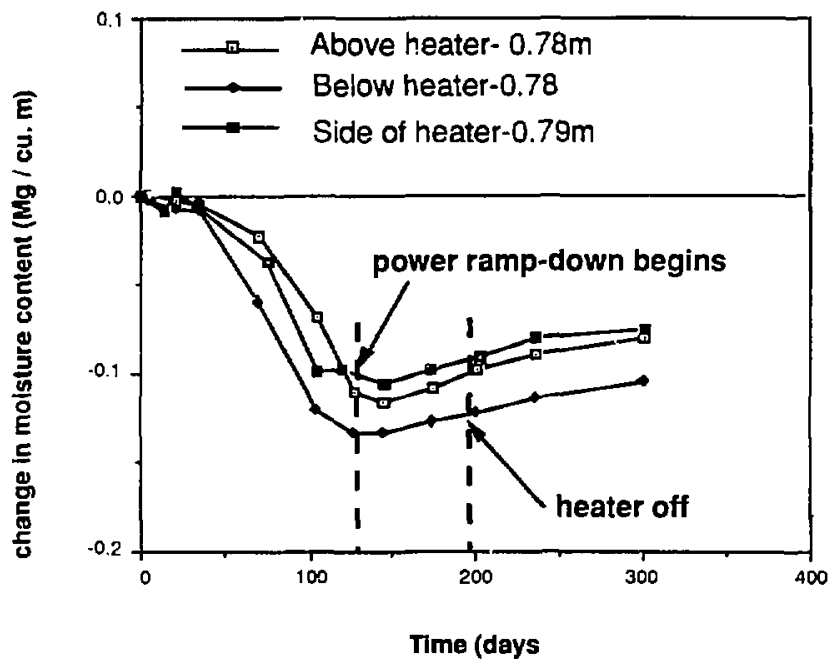

Figure 24. Changes in moisture content as a function of time for three points approximately equidistant from the heater's center line. 


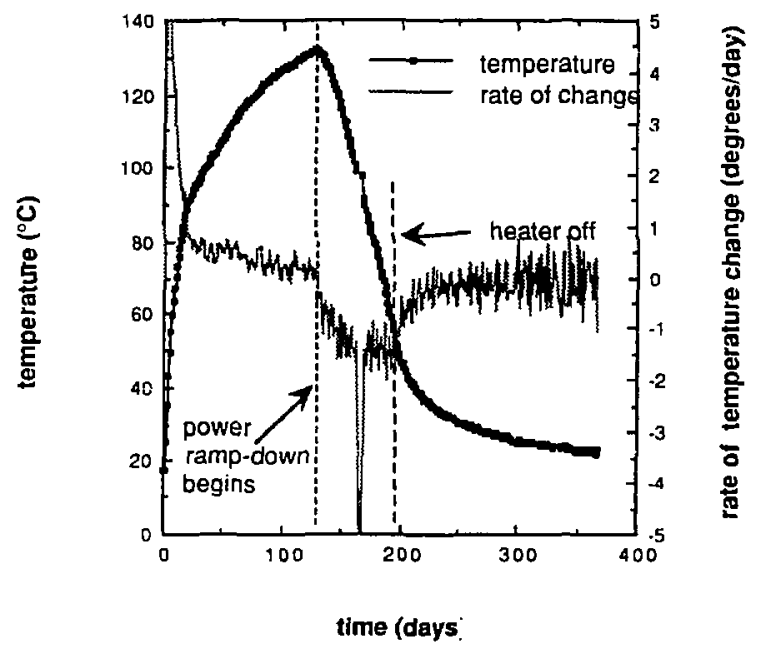

Figure 25. Temperatures and rate of temperature change for a point within borehole P-3 located at a radial distance of $0.77 \mathrm{~m}$ from the heater.

\section{Conceptual models for dying and re-wetting behavior}

The models to be proposed below ere, to a large extent, similar to the starting conceptual model shown in Figure 1; this indicales the results discussed above generally validate the starting conceptual model. The most significant modifications to the pre-test conceptual understanding concerned the contribution of the gas phase to re-wetting of the fractured rock mass. Tes! results showed re-wetting occuring along iractures which were considered to be dry. Re-examination of the re-wetting behavior predicted by our numerical models showed substantial vapor flux along fractures from wet to dry regions. Other important observations that can be made is that the distribution of changes in moisture was not radially symmetric relative to the heater axis. It has been shown that the rock above the heater dried slower but re-wetted faster than the rock below the heater. Fractures seem to have increased the rate of drying and re-wetting.

The conceptual models showr in Figure $25 \mathrm{~A}$ and $\mathrm{B}$ propose explanations for these observations. The model in Figure $25 \mathrm{~A}$ proposes a conceptual model for the case of a vertical fracture striking parallel to the heater. As temperatures increase, the evaporation rate of pore water increases. As a result, the pressure of the vapor phase also increases and drives gas flow. Note that the pressure rise elevates the boiling point temperature. In unfractured rock, the vapor phase flow is primarily outward because gas pressure is greater towards the heater; 
however, near a tracture vapor phase flow is preferentially towards the fracture because the fracture acts as a pressure sink. At a given temperature, rock near a low pressure, high permeability boundary will dry faster because vapor has a shorter distance to travel through a relatively low permeability matrix; therefore. rock near fractures dries faster than the surrounding rock as shown in the conceptual model. Once the hot gas is in the (approximately) vertical fracture it will tend to flow upwards (due to buoyancy) because fractures are at ambient pressure; the net result is that more steam is likely to condense above the dry zone than in other parts. This mechanism may ba one reason why the rock above the heater dried slower and re-wetted faster than the rock below.

The drainage of steam condensate also plays a role in the proposed model. Water condensing in the fractures will start draining vertically downward. Note in Figure $25 \mathrm{~A}$ that for the steam flow and condensate flow directions shown along the fracture, the upwards penetration of the dry region will be slowed by the condensate that drains back to the boiling zone. Below the heater, the dry region can penetrate more because the condensate drains away from the boiling region. The authors believe that the wetting region below the dry zone was not detectable during this test because imbibition was slow relative to the velocity of liquid water draining down the fractures; however, the lower wetting region is likely to extend farther below the heater than the wetting region above because of condensate drainage along longer paths. The net result of this conceptual flow system is that there is more imbibition of condensate above the dry zone because it stays in contact with the matrix for longer times than below the dry zone where it can escape; these two conditions favor more imbibition of condensate above the heater. Figure $25 \mathrm{~B}$ illustrates this effect better by depicting flow directions for the case of a fracture striking perpendicular to the heater axis. The net effect is that the hot dry rock zone intercepted by the fracture plane acts as an umbreiia that stops the downward flow of condensate and gradually sheds it to the sides. This model has also been used to explain temperatures wnich remained near the boiling point for long periods of time during the test (Lin and others, 1990; Ramirez and others, 1990). Drips of condensate along fractures are also shown in the conceptual model as an additional mechanism that could slow the penetration (upwards and sideways) of the dry region. 


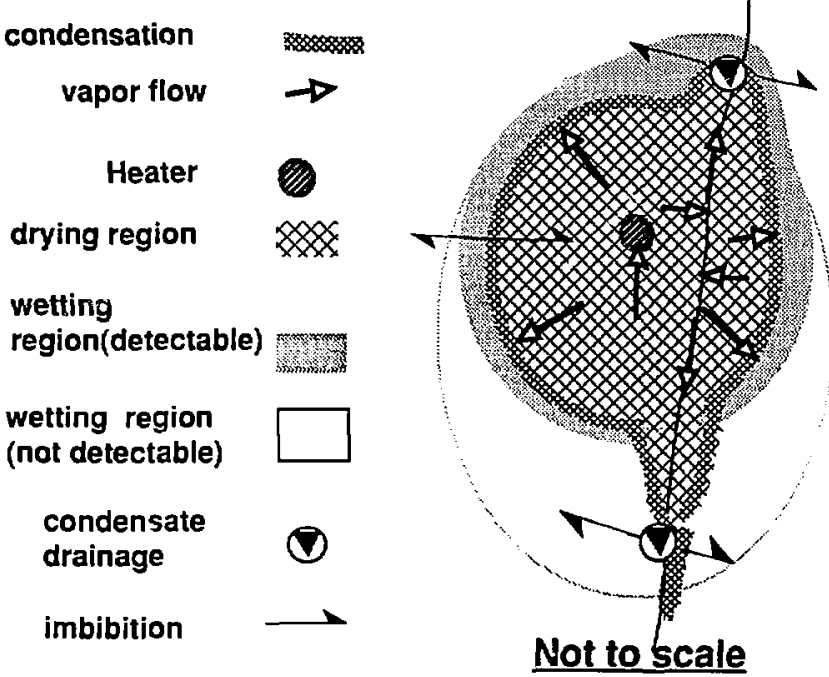

Figure 25 A. Conceptual model proposed for the flow above and below the heater for the case of a fracture striking parallel to the heater axis. A transect along a matrix block intersected by a fracture is shown.

During the rampdown of power to the heater, temperaiures around the heater responded quickly to the decline in heat load. Boiling became less vigorous and ceased roughly midway into the rampdown. During this time the moisture content of the dried-out zone began to slowly incroase in moisture content with regions above and to the sides of the heater gaining moisture faster than regions below the heater. Figure 26 is a simplified schematic depicting the main re-wetting features which may have given rise to the differences in re-wetting rates. It should be noted that as the heater power was reduced, boiling continued even though at decreasing rates. Even atter boiling ceased, heating of the rock around the heater continued to facilitate evaporation. Recall that above the heater the return flow of condensate in fractures slowed the progress of the boiling front away from the heater while below the heater condensate drainage in the fractures had little effect on the rate of drying of the matrix. If the region above the heater was being heated from a linear source of heat, there would be a critical heat flux rate at which the return flow of coridensate would be balanced by the rate of boiling. For heat flux rates in excess of this critical rate, 
the boiling front would move away from the heater. For heat flux rates less than condensation

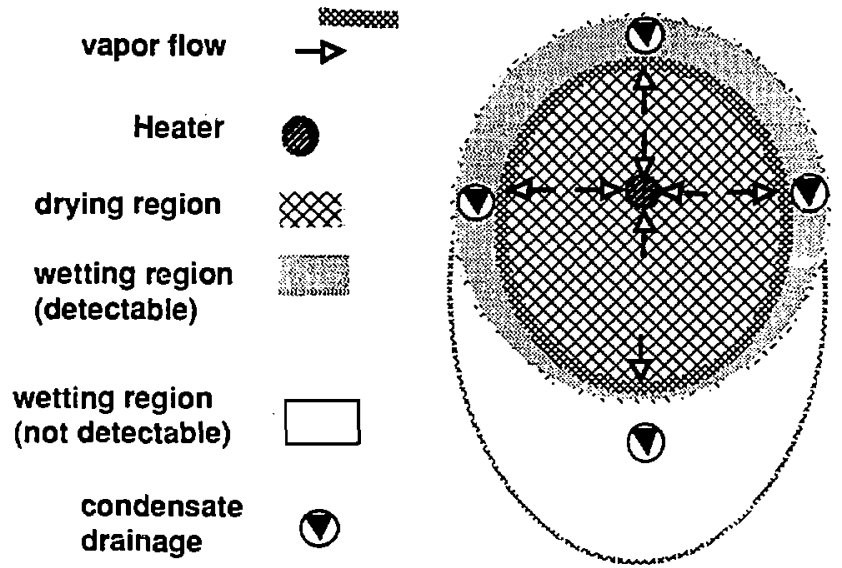

the

\section{Not to Scale}

Figure $25 \mathrm{~B}$. Proposed flow phenomena for the case of a fracture perpendicular to the heater axis. The view is along the fracture plane.

critical rate, the boiling front would move toward the heater. For this test, radial heat flow from the heater complicates this relationship between heat flux and the velocity of the boiling front. However, it should be apparent that as the heating rate is reduced, the boiling front eventually begins to recede towards the heater. To the sides of the heater, the situation is somewhat more complex as conderisate draining down fractures from regions above begins to re-wet the rock $a^{+} \Rightarrow$ rate faster than the boiling rate. Below the heater the rock is essentially shielded from condensate draining down fractures due to the presence of the umbrella provided by the overlying dried-out zone. Therefore, re-wetting of the rock below the heater occurs without the benefit of liquid water movement in fractures. Above the heater, liquid water movement along fraclures does contribute to re-wetting because longer residence times for the condensate allow more imbibition, and condensate does not have to travel through a dried out zone to reach the matrix above the heater. 


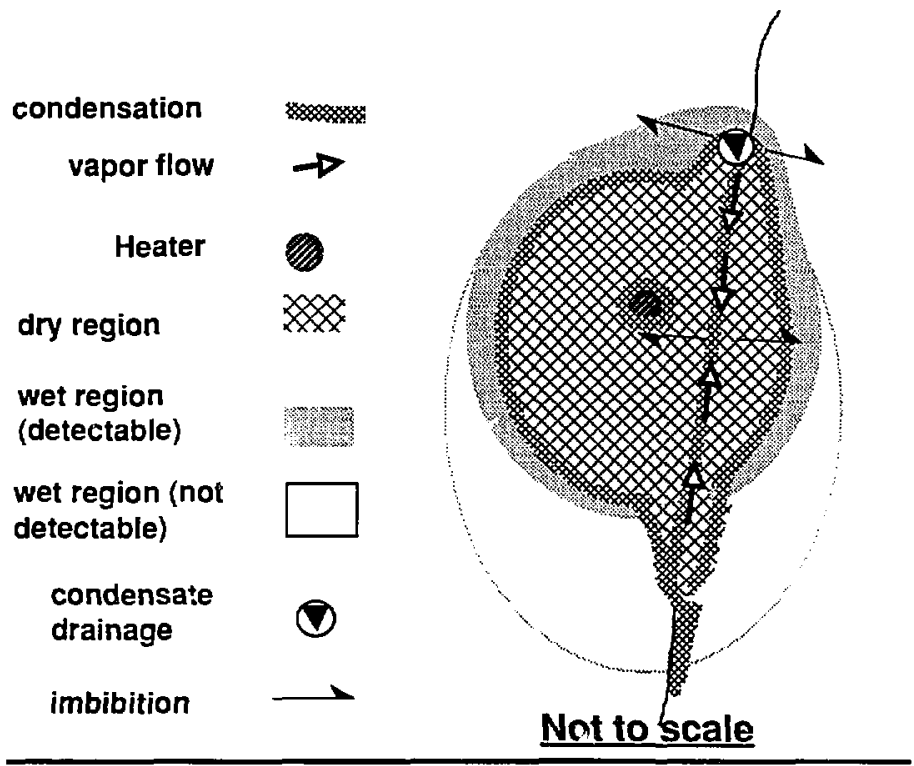

Figure 26. Proposed conceptual model of the mechanisms which dominate the re-wetting process of the dry region during cool down of the rock mass. A transect along a matrix block intersected by a fracture is shown.

In the numerical modeling study it was found that simple matrix imbibition cannot adequately account for the moisture movement observed during the rampdown and post-heating phases. Moreover, below the heater, re-wetting rates were observed to be greater in regions of higher fracture density. The fractures appeared to be contributing significantly to re-wetting even though it is unlikely that liquid flow was occuring in the fractures below the heater. In the numerical modeling study it was noted that saturation gradients in the matrix are associated with relative humitity gradients in the gas phase in the fractures as well as the matrix. It was found that large mass flowrates of vapor occurred down the relative humidity gradient due to binary diffusion of water vapor and air.

Darcy flow (i.e., driven by pressure gradients) of air through fractures may have also brought humidity to the dry region. As the hot, dry rock cooled and water vapor condensed, the gas-phase pressure dropped. These lower pressures would drive flow of vapor in the fractures. Capillary coridensation of the water vapor occured along the fracture faces in the dried-out zone with subsequent 
movement of this condensate into the matrix due to imbibition. Relative to an unfractured rock mass, the presence of fractures (and the very high effective mobility of vapor driven by binary diffusion) effectively shortens the distance over which water must be imbibed in order to re-wet the dried-out region. Vapor phase movement in fractures contributed to re-wetting behavior throughout the fractured rock mass. Therefore, even for regions above and to the sides of the heater where liquid movement in the fracture: was re-wetting the rock, binary diffusion driven flow and Darcy flow in fractures were also contributing to rewetting behavior.

\section{Summary and conclusions}

Thermal neutron logs have been collected to monitor changes in moisture content within a welded tuff rock mass heated by an electrical heater. The heater remained energized for 196 days. The heater power for the first 128 days was maintained at approximately $3.3 \mathrm{~kW}$; the power was then gradually decreased to $0.0 \mathrm{~kW}$ during a 68 day period. Thermal neutron measurements were made before, during and after the heater was turned on. For each borehole, the differences between the "betore" and "after" measurements have been calculated ("after" heating minus "before" heating, or "during ramp down" minus "last day of heating"). A spatial filter was applied to each difference log to reduce Poisson fluctuations in the number of neutrons detected by the probe. The imprecision estimate for the filtered points is $+/-0.003 \mathrm{Mg}$. of water per $\mathrm{m}^{3}$ ( $95 \%$ confidence level). The possibility of changes in the moisture content of the grout column within the sampling boreholes introduces an unknown but possibly significant error in the measured values. It is possible that grout column changes may be distorting the moisture content measurements of the rock adjacent to the grout column.

The difference traces show that the predicted conceptual model is valid in general terms. The data show that an arbitrary point in rock above the heater first increases its moisture content as steam generated closer to the heater condenses in cooler adjacent areas. Tl:is "halo" of increased moisture subsequently subsides as the temperatures and evaporation rates at this point increase. The diameter of the drying region grows faster at first, and then at a progressively slower rate as the volume of rock to be heated increases. As the heater power decays the moisture content slowly increases. As expected, the drying front appears to have penetrated more rapidly along fractures during the maximum power stage. Also, re-wetting is more rapid near fractures during the cool-down and post-heating stages of the test.

Plots of change in moisture content as a function of radial distance show that the changes are not always radially symmetric relative to the $i$ aater borehole axis. The data show that there are significant differences in drying and rewettiang behavior of rock above and below the heater. The rock below the heater dried out faster than the rock above the heater at equal radial distances. During the power ramp-down and post heating phases, the rock directly above the heater re-wetted at a slightly faster rate than the rock below.

Conceptual models have been developed based on the results shown here and in coniunction with the numerical modeling study to explain differences in the drying and re-wetting behavior above and below the heater. In general, water 
vapor generated in a matrix block moves towaros the closest fracture face (or surface of the heater borehole if the block is adjacent the borehole). Upon entering the fracture. water "apor tends to move radially outward througl, the fracture system until encountering condensation conditions. Due to the heater borehole moisture coilection system and condensation on the heater packer, some of the vapor in the fractures moves radially inward towards the heater hole. Water which condenses above the heater drains downward through the fractures. Much of this downward flow intersects the boiling zone and is reboiled, thereby slowing the upward progress of the boiling front. Some downward flow of condensate was observed to be re-boiled at the lower flank of the heater, thereby stabilizing the boiling front at that location. Water which condenses below the heater drains away from the boiling zone. Because matrix imbibition is slow relative to the condensate generation and drainage rates, most of the downward drainage of condensate uslow' the heater leaves the local system before it can be subsequently re-isiled. It was also observed that the boiling zone effettive acts as an "umbrella" shielding the rock below the heater from the downward drainage of condensate generated above the heater. Fie-wetting of the rock above the heater and to one side of the heater was observed to be partially the result of condensate drainage in fractures.

Throughout the fractured rock mass re-wetting also occired via binary diffusion of water vapor (driven by relative humidity gradients) and via Darcy flow (driven by pressure gradients). As this water vapor reaches drier rock, it condenses along the fracture faces (by capillary condensation) and is imbibed by the miatrix.

\section{Recommendations for future work}

As a result of the work described in this report, we can propose recommendations for the use of neutron logging tools in future tests of the near field environment around a heater. The effect of the grout/liner system needs to be better understood and/or minimized. It can be minimized by: 1) reducing the size of the annular space filled with grout, and 2) using a probe with a substantially bigger sampling volume. If a cement grout is used again, there is a need to establish quantitatively the influence that the grout column has on the measured values of moisture content; this can be done via a calibration process wherein the moisture content of large welded tuff cores (with grout sealed boreholes) is determined as a function of temperature by correlating weicht changes vs thermal neutron counts. The test results suggest that there is an asymmetrical distribution of moisture content that develops around the heater To better characterize this distribution, we sugjest that radial boreholes (i.e. parallel to heater borehole radii) be considered; in particular, a radial vertical borehole is strongly recommended. Moisture measurements also need to be made well below the boiling zone in order to track the vertical and lateral extent over which condensate drainage in fractures can occur. 


\section{Acknowledgments}

The authors want to acknowledge the contributions of colleagues who participated in data collection: Kenrick Lee, Wunan Lin, Nai-Hsien Mao, Donald Towse. Tzou-Shin Ueng, and Donald Watwood. Dwayne Chesnut, Paul kasameyer and Jesse Yow Jr. provided helpful review comments which substantially improved the manuscript. Wunan Lin provided data on porosity of core samples. Prepared by Yucca Mountain Site Characterization Project (YMP) participants as part of the Civilian Radioactive Waste Management Program. YMP is managed by the Yucca Mountain Site Characterization Project Office of the U. S. Department of Energy, Las Vegas, Nevada.

\section{References}

Buscheck, T. and J. Nitao (1988) Preliminary Scoping Calculations of Hydrothermal Flow in Variably Saturated. Fractured, Weided Tuff During Engineered Barrier Design Test at the Yucca Mountain Exploratory Shaft Test Site. UCID-21571. Lawrence Livermore National Laboratory. Livermore, CA. NNA.890224.0009

Daily, W., W. Lin, and T. Buscheck (1986) "Hydrclogy of Topopah Spring Tuff -Laboratory Measurements." J. Geophys. Res., Vol. 92, No. B8, pp. 7854-70u4. HQS.880517.2416

Daily, W. D. A. Ramirez, and T. Ueng (1989) "Chapter 1: High Frequency Electromagnetic Tomography", in Ramirez, A. L., and Wilder, D. G. (eds. ) Prototype Engineered Barrier Sysiem. Field Tests. Progress. Report through November 1, 1988. Lawrence Livermore National Laboratory UCID-21640. Livermore, CA. NNA.910207.0024

Lee, K. and T. Ueng (1989) "Chapter 3: Permeability Tests", in Famirez, A. L., and Wilder, D. G. (eds. ) Prototype Engineered Barrier System Field Tests. Frogress Report through November 1. 1988. Lawrence Livermore National Laboratory UCID-21640, Livermore, CA. NNA.910207.0024

Lee, K. and T. Ueng (1989) "Chapter 4: Heater Assembly", in Ramirez, A. L., and Wilder, D. G. (eds. ) Prototype Engineered Barrier System Field Tests. Progress Report through November 1, 1988. Lawrence Livermore National Laboratory U' 'D-21640, Livermore, California. NNA.910207.0024

Lin W. $\{1990\}$, Personnal communication dated 3/1/90. NNA.90081尺 0016

Lin, W., Ramirez, A., and D. Watwood (1990) Temperature Męasurements from Prototype Enoineered Barrier systen Field Test. Lawrence Livermore National Laboratory UCRL-ID-104757, Livermore, CA. (Readily available)

Lin, W., Ramirez, A., and D. Watwood (1989) "Chapter $1:$ Temperature Measurements in GTunnel", in Ramirez, A. L., and Wilder, D. G. (eds. IPrototype Engineered Barrier System Fieid Tests. Progress Report through November 1 1988. Lawrence Livermore National Laboratory UCID-21640, Livermore, CA. NNA.910207.0024 
Nitao, J. J. (1988) Numerical Modeling of the Thermal and Hydrological Environment Around a Nuclear Waste Package Using the Equivalent Continusum Approximation: Horizontal Emplacement UCID-21444, Lawrence Livermore National Laboratory, Livermore, CA. NNA.890317.0021

Nitao, J. J., and T. Buscheck (1989) On the Movement of a Liquid Front in an Unsaturated. Fractured Porous Medium. Part L UCID-21714, Lawrence Livermore National Laboratory, Livermore, CA. NNA.891130.0050

Ramirez, A. L., T. A. Buscheck, R. Carlson, W. Daily, V. R. Latorre, K. Lee, W. Lin, N. Mao, D. Towse, T. Ueng, and D.Watwood, (1990), "Prototype Heater Test of the Environment Around a Heater", UCRL-101693, Lawrence Livermore National Laboratory, Livermore, CA. (Readily available)

Ueng, T. and D. Towse (1989) "Chapter 10 : Fracture Analysis", in Ramirez, A. L., and Wilder, D. G. (eds. ) Prototype Engineered Barrier System Field Tests. Progress Report through November 1. 1988. Lawrence Livermore National Laboratory UCID-21640, Livermore, CA. NNA.910207.0024

Yow , J. Jr. (1985) Concept for Waste Package Elvironment Tests in the Yucca Mountain Exploratony Shatt, UCID-20450, Lawrence Livermore National Laboratory, Livermore, CA. NNA.870522.0041

Zimmerman, R. M., and R. E. Finley (1986) Summany of Geomechanical Measurements Taken in and Around the G-Tunnel Underoround Facility. NTS. SAND86-1015, Sandia National Laboratories, Albuquerque, NM, 143p. NNA.870526.0015 
The following number is for Office of Civilian Radioactive Waste Management Records Management purposes only and should not be used when ordering this document:

Accession Number: NNA.910701,0097 